\title{
FABRICATION AND EVALUATION OF ORAL CONTROLLED RELEASE OF MUCOADHESIVE ALGINATE MICROBEADS CONTAINING FLUVASTATIN SODIUM
}

\author{
VENKATA RAMANA REDDY $\mathrm{K}^{1 *}$, NAGABHUSHANAM MV \\ ${ }^{1}$ Department of Pharmaceutics, KVK College of Pharmacy, Ranga Reddy, Telangana, India. ${ }^{2}$ Department of Pharmaceutics, Hindu College of \\ Pharmacy, Guntur, Andhra Pradesh, India. Email: srikanth.papa@gmail.com
}

Received: 09 October 2019, Revised and Accepted: 23 October 2019

\section{ABSTRACT}

Objective: The aim of this study is to prepare oral controlled release (CR) of mucoadhesive alginate microbeads encapsulating fluvastatin by gastroretention technology.

Methods: The mucoadhesive microbeads containing fluvastatin were produced using emulsification internal gelation technique. The effect of different variables such as sodium alginate concentration and its combination with other hydrophilic polymers, and the effect of various curing agents on particle size, entrapment efficiency, and in vitro studies were evaluated.

Results: There was no marked change in drug entrapment efficiency, and dissolution studies occur during the stability studies of fluvastatin. The in vitro results give data that improvement in the CR of the drug from microbeads compared with marketed tablet. Hence, in this regard, to minimize the frequency of drug administration to reduce side effects. The optimum condition for the preparation of stable alginate beads and produce CR manner was occurred at a higher concentration of combined polymer mixture in equal ratios, i.e., $3 \% \mathrm{w} / \mathrm{v}$. Infrared spectroscopic study (Fourier transform infrared) confirmed the no incompatibility between drug and other excipients. X-ray diffraction study and differential scanning calorimetry were provided evidence that successful entrapment of drug into the alginates microbeads and drug converted into amorphous nature. The efficiency of mucoadhesion strength of microbeads was determined by wash-off study.

Conclusion: The kinetic modeling of the release data indicates drug release from the microbeads follow anomalous transport mechanism and super Case-II transport mechanism. Drug release is a function of $\mathrm{pH}$ dependent and controlled drug release depends on type and concentration of polymer blend and curing agents. The release kinetics of drug from the alginate beads followed zero order.

Keywords: Fluvastatin, Emulsification internal gelation, Sodium alginate, Hydroxypropyl methylcellulose K4M, In vitro wash off study and swelling index.

(c) 2019 The Authors. Published by Innovare Academic Sciences Pvt Ltd. This is an open access article under the CC BY license (http://creativecommons. org/licenses/by/4. 0/) DOI: http://dx.doi.org/10.22159/ajpcr.2019.v12i12.35991

\section{INTRODUCTION}

Orally administrated solid dosage forms possess large individual differences in the rate of bioavailability of many drugs, this occurs mostly because of the large variable gastrointestinal (GI) transit time of a tablet/capsule. In contrast to this, mucoadhesive drug delivery system designed to reduce both intra- and inter-subject variability in absorption of drug, to prevent sudden release of drug and provides drug release in controlled manner.

The polymers and transporters utilized in the arrangement are nontoxic, promptly accessible, and usually noncostly. Among completely various different polymers, Na-alginate remains as a polymer of decision for bead production. It is a bioerodible polyacid that has gained a unique property of gel network inside the sight of multivalent cations, for example, aluminum ions (trivalent) and calcium ions (divalent) in fluid media that happen chiefly at intersections in the G-G sequence rich chain region named as the "egg box junction." Bead production is gotten by the inclusion of the medication into a gel dispersion system, and the hydrophilic colloids at that point connect with polyvalent metal ions to obtain insoluble colloidal complexes (calcium alginate), drops that may cause to accelerate in the formation of cross-linked beads.

For soluble drug, carbopol gel could extend the release time but release pattern has significant fluctuation. Hence, in this study, polymer blend used containing hydroxypropyl methylcellulose (HPMC) K4M and sodium alginate was used in equal ratios and which acts as a matrix former to improve the rate of release of fluvastatin sodium from matrices. For many medications that are ingested basically from the proximal small intestine, controlled discharge in stomach would bring about improved [1-3] the rate of bioavailability. Different methodologies available to increase the gastrointestinal residence time, few of which include floatation system or swellable system, gas rafting system, and mucoadhesive system.

Fluvastatin sodium is an antilipidemic agent that competitively inhibits hepatic enzyme 3-hydroxy-3-methylglutaryl-coenzyme a reductase. It belongs to a class of medications called statins and is used to reduce plasma cholesterol levels and prevents cardiovascular diseases [4]. Its short biological half-life $(3 \mathrm{~h})$ and but it possesses low therapeutic concentration at the target site due to low rate of bioavailability (24\%-29\%) because of extensive presystemic metabolism, less GI residence time. The nature of drug is lipophilic. Nonetheless; this compound has a variable elimination half-life time around $1-6 \mathrm{~h}$ in people, requiring a dosing recurrence 20-40 $\mathrm{mg}$ twice a day. In the perspective on these attributes, numerous endeavors have been made to develop sustained-release (SR)/CR preparation with broadened clinical impacts and diminish dosing recurrence [5] and also prolong the duration of action of drug.

The emulsification internal gelation commonly formed by cross-linking of sodium alginate, yet the subsequent aluminum alginate microbead is absolutely compact, creating it very difficult to control the release of medication for a long period of time compared to other curing agents. These issues are generally confined by blending sodium alginate with completely other polymers, for instance, HPMC K4M, sodium carboxymethyl cellulose, and Carbopol 934P. 
Sodium alginate polymer is a linear polysaccharide and unbranched, biocompatible, versatile, and non-toxic matrix of gel that protects the active components of factors such as humidity and heat and thereby improving stability and bioavailability [6]. Because of non-regular block carboxyl groups with the sodium alginate chains, these chains are highly prone to cross-link with divalence/trivalence cations which enables to form reticular hydrogel structure; hence, sodium alginate is broadly used mainly in application of the controlled drug delivery system nowadays. HPMC is a non-ionic cellulose-based compound because of its surface activity and high swelling capacity it makes to enhance drug loading and prolongs drug release.

It was discovered that the biocompatible microspheres had additional high selectivity for discharge of drug substance, in which they restrict drug release at the simulated gastric fluid $(\mathrm{pH}=1.2)$, however, permitted full maximum rate of the drug at the premises of higher $\mathrm{pH}$ atmosphere, i.e., intestines, implying that the materials are harmless and safe as a drug carrier for controlled release (CR) pattern of drug. This kind of science is reasonable for financially savvy make, prompting a desire that the methodology might be useful for scale-up to industrial production.

\section{MATERIALS AND METHODS}

\section{Materials}

The pure drug fluvastatin was obtained from AurobindoPharma Limited, Hyderabad, Telangana state, India. HPMC, sodium alginate was purchased from HiMedia, Mumbai, Carbopol 934, barium chloride $\left(\mathrm{BaCl}_{2} \cdot 2 \mathrm{H}_{2} \mathrm{O}\right)$, calcium chloride $\left(\mathrm{CaCl}_{2} \cdot 2 \mathrm{H}_{2} \mathrm{O}\right)$, aluminum chloride $\left(\mathrm{AlCl}_{3} \cdot 6 \mathrm{H}_{2} \mathrm{O}\right)$, ethanol, and chloroform solution were obtained from QualigensFine Chemicals, Mumbai. All chemical agents used belonging to analytical high-grade quality.

\section{Equipments}

Digital electronic weighing balance (0.1 mg sensitive), Sonicator (Remi model, Mumbai, India), Sigma Blade Homogenizer (Remi model, India), Dessiccator (Borosilicate, Mumbai), Tablet disintegrating test apparatus (USP model, India), Dissolution test apparatus USP (model TDT-08L, Electro-lab, Mumbai, India), and Sonicator, Remi model, India. Double beam ultraviolet (UV)-visible spectrophotometer, Shimadzu, scanning electron microscope (SEM; S4100, Hitachi, Japan), X-ray diffractometer, Bruker spectrophotometer (Model-220, Germany) and Syringe needle 23 G, etc.

\section{Preparation of fluvastatin microbeads}

The fluvastatin based alginate microbeads were prepared by choosing emulsification internal gelation method. The mucoadhesive microbeads were prepared by taking fluvastatin $40 \mathrm{mg}$ dissolved in purified mineral water and this solution was added to white viscous solution which is already prepared and this contained sodium alginate polymer solution. This polymer solution is prepared by taking sodium alginate polymer and dissolved in water by subjecting to homogenization process until sodium alginate is completely dissolves then keeps this homogenous polymer viscous solution inside sonicator to remove air bubbles completely. To the above physical mixture solution which is placed in a beaker, add selected cross-linking agent at $5 \% \mathrm{w} / \mathrm{v}$ concentration slowly into above glass beaker which is stirred with high frequency Remi modeled sigma blade homogenizer and keep on rotation for long time until it forms smooth, fine viscous solution completely and again keep the above solution for sonication up to $1-2 \mathrm{~h}$ to get free bubble solution finally. The above physical mixture solution containing drug with selected polymer of known concentration and cross-linking agent take into $10 \mathrm{ml}$ syringe which is fixed with needle 22 gauze and pressed/ extruded dropwise into $250 \mathrm{ml}$ glass beaker which containing mixture of $100 \mathrm{ml}$ light liquid paraffin oil (acts as a emulsifying agent) with $1.5 \% \mathrm{w} / \mathrm{v}$ concentration of span 80 and glacial acetic acid at $0.2 \% \mathrm{w} / \mathrm{v}$. During the addition of drug-based polymer viscous solution dropwise, and it was sure to keep the minimum $10 \mathrm{~cm}$ distances between glass beaker and tip of needle throughout the process. The process of homogenization under $600 \mathrm{rpm}$ by rotating with blade homogenizer was maintained continuously. After specified time, the above solution was filtered through filter paper placed over funnel, on filtration, it will form residue of insoluble high viscous smooth solid product and it was washed carefully 3-4 times with n-Hexane or chloroform solution to remove sticky fatty material on surface of small microbeads and these formed microbeads placed inside dessiccator until microbeads becomes completely dried.

In this current article, other hydrophilic polymers were also incorporated along with sodium alginate in equal ratios than alone sodium alginate polymer and different curing agents were added at $5 \%$ $\mathrm{w} / \mathrm{v}$ concentration on optimized batch to evaluate the change in drug release pattern and other parameters, which were clearly mentioned in following Table 1.

\section{CHARACTERIZATION STUDIES}

\section{Size distribution and size analysis}

For determination of size distribution analysis, $200 \mathrm{mg}$ of the crosslinked fluvastatin alginate microbeads of various sizes in a formulation were subjected to sieving method using a range of standard sieves grades and arranged one by one according to their mesh size and start

Table 1: Formulation composition and physicochemical properties of prepared fluvastatin microbeads

\begin{tabular}{|c|c|c|c|c|c|c|}
\hline Polymers used & $\begin{array}{l}\text { Batch } \\
\text { code }\end{array}$ & $\begin{array}{l}\text { Core: coat } \\
\text { ratio }\end{array}$ & Yield (\%) & $\begin{array}{l}\text { Average particle } \\
\text { size }\end{array}$ & $\begin{array}{l}\text { Drug } \\
\text { content }\end{array}$ & $\begin{array}{l}\text { Percentage } \\
\text { entrapment efficiency }\end{array}$ \\
\hline \multirow[t]{4}{*}{ Sodium alginate } & FSF1 & $1: 01$ & 91.68 & $132.55 \pm 0.07$ & $44.96 \pm 0.02$ & $89.92 \pm 0.09$ \\
\hline & FSF2 & $1: 1.5$ & 93.89 & $146.36 \pm 0.05$ & $37.94 \pm 0.04$ & $94.85 \pm 0.06$ \\
\hline & FSF3 & $1: 02$ & 95.13 & $154.44 \pm 0.03$ & $31.82 \pm 0.05$ & $96.42 \pm 0.04$ \\
\hline & FSF4 & $1: 03$ & 96.47 & $168.47 \pm 0.06$ & $24.46 \pm 0.03$ & $97.84 \pm 0.07$ \\
\hline \multirow[t]{3}{*}{ Sodium alginate+HPMC K4M } & FSF5 & $1: 01$ & 92.12 & $135.13 \pm 0.05$ & $44.13 \pm 0.09$ & $88.26 \pm 0.05$ \\
\hline & FSF6 & $1: 1.5$ & 92.35 & $157.24 \pm 0.09$ & $37.34 \pm 0.08$ & $93.95 \pm 0.09$ \\
\hline & FSF8 & $1: 03$ & 96.45 & $180.29 \pm 0.07$ & $23.41 \pm 0.05$ & $93.64 \pm 0.04$ \\
\hline \multirow[t]{4}{*}{ Sodium alginate + carbopol 934P } & FSF9 & $1: 01$ & 92.18 & $139.44 \pm 0.06$ & $46.56 \pm 0.05$ & $93.12 \pm 0.06$ \\
\hline & FSF10 & $1: 1.5$ & 94.56 & $156.47 \pm 0.09$ & $37.66 \pm 0.09$ & $92.90 \pm 0.05$ \\
\hline & FSF11 & $1: 02$ & 96.88 & $168.39 \pm 0.05$ & $31.25 \pm 0.06$ & $94.39 \pm 0.04$ \\
\hline & FSF12 & $1: 03$ & 98.32 & $179.33 \pm 0.06$ & $23.47 \pm 0.04$ & $93.38 \pm 0.06$ \\
\hline Sodium alginate $+\mathrm{NaCMC}$ & FSF13 & $1: 01$ & 92.47 & $140.53 \pm 0.02$ & $44.38 \pm 0.07$ & $89.76 \pm 0.02$ \\
\hline \multirow[t]{2}{*}{$1100-1900 \mathrm{Cps}$} & FSF14 & $1: 1.5$ & 96.28 & $156.33 \pm 0.04$ & $37.66 \pm 0.04$ & $94.15 \pm 0.03$ \\
\hline & FSF15 & $1: 02$ & 96.79 & $164.46 \pm 0.07$ & $31.46 \pm 0.08$ & $95.33 \pm 0.05$ \\
\hline Sodium alginate+HPMC K4M & FSF17 & $1: 03$ & 96.36 & $174.32 \pm 0.05$ & $23.27 \pm 0.04$ & $93.08 \pm 0.07$ \\
\hline Sodium alginate+HPMC K4M & FSF18 & $1: 03$ & 96.23 & $167.25 \pm 0.05$ & $23.43 \pm 0.03$ & $93.72 \pm 0.06$ \\
\hline
\end{tabular}

*Batches FSF1 to FSF16 cured with 5\% $\mathrm{AlCl}^{3+}$ with different polymersonly and FSF17 and FSF18 batches containing sodium alginate with HPMC K4M. and that cured with $5 \% \mathrm{w} / \mathrm{v}$ of $\mathrm{BaCl}^{2+}$ and $5 \% \mathrm{CaCl}^{2+} \mathrm{w} / \mathrm{v} .{ }^{*}$ All readings were taken in triplicate manner, i.e., $\mathrm{n}=3$. Mean \pm SD. NaCMC: Sodium carboxymethyl cellulose, HPMC: Hydroxypropyl methylcellulose 
the machine continuously according to the standard procedure. The amount of uniformed microbeads which were retained on different individual sieves was taken out and weighed accurately. Finally, the mean particle size of the fluvastain microbeads was determined by given the following equation. Mean particle size $=\frac{\sum(\text { Mean particle size of fraction } \times \text { weight Fraction })}{\sum(\text { Weight fraction })}$

\section{Percentage of yield}

Percentyield defined as the percent ratio of practical yield to the theoretical yield. Mathematically, it is computed from the following equation.

Percentage of yield $=\frac{\text { Practical yield }}{\text { Theroteical yield }} \times 100$

\section{Estimation of drug content of microbeads}

Accurately $100 \mathrm{mg}$ of microbeads were exactly weighed and shifted to a cleaned dry mortar and powdered by continuous grinding and dissolved in $100 \mathrm{ml}$ of freshly prepared $\mathrm{pH} 6.8$ phosphate buffer solution and filtered, suitably diluted the absorbance of the above solution, absorbance was measured at $304 \mathrm{~nm}$ by UV-visible spectrophotometer for fluvastatin.

\section{Entrapment efficiency of microbeads}

Entrapment efficiency was resolved using the formula. For calculation of drug content, $40 \mathrm{mg}$ of beads were placed in $100 \mathrm{ml}$ of 6.8 phosphate buffer for complete swelling at $37^{\circ} \mathrm{C}$. The fluvastatin based alginate beads were crushed in a glass mortar with pestle and the above solution was then kept for $2 \mathrm{~h}$ to extract the drug completely and centrifuged to separate polymeric debris using centrifuge apparatus for $30 \mathrm{~min}$. The solution was filtered, the clear supernatant solution was measured fluvastatin content using a UV-visible spectrophotometer at $304 \mathrm{~nm}$.

$$
\begin{gathered}
\text { Entrapment efficeincy }=\frac{\text { Estimated percentage drug content }}{\text { Theoritical percentage drug content }} \times 100 \\
\text { Drug loading }=\frac{\text { Total amount of drug in microbeads }}{\text { Weight of microbeads }} \times 100
\end{gathered}
$$

Estimated percent drug content was determined from the analysis of $100 \mathrm{mg}$ microbeads, and the theoretical percent drug content was calculated from the utilized core:coat ratio in the formulation of microbeads.

\section{Morphological characterization of microbeads (SEM studies)}

Tests were sputter-covered with gold under a vacuum before perception with a SEM at an increasing speed voltage of $10 \mathrm{kV}$.

\section{Fourier transform infrared (FTIR) spectra analysis studies} Infrared spectra were recorded by utilizing a TENSOR 27 FTIR spectrometer (Bruker, Horiba, Oberursel, Germany). Scans were recorded more than $400-4000 \mathrm{~cm}^{-1}$ wavenumbers with a resolution of $2 \mathrm{~cm}^{-1}$.

\section{X-ray diffraction (XRD) studies}

Pure fluvastatin sodium, microbeads loaded drugs were analyzed using an X-ray diffractometer (D8, Bruker, Germany) in the $2 \theta$ range $5-60^{\circ}$ with a scanning velocity of $2^{\circ} \mathrm{min}^{-1}$.

\section{Differential scanning calorimetry (DSC) studies}

For the determination of DSC studies, the microbeads of known quantity $(2 \mathrm{mg})$ were heated from $40^{\circ} \mathrm{C}$ to $275^{\circ} \mathrm{C}$ using a temperature rate of $10^{\circ} \mathrm{C} / \mathrm{min}$. A nitrogen purge of $100 \mathrm{ml} / \mathrm{min}$ was fixed.

\section{Determination of swelling index}

It was determined by measuring the difference between the initial diameter of the microbeads and final diameter of the beads at time $t$. It can be calculated by the following equation.

$$
\mathrm{Sw}=\frac{\left(\mathrm{W}_{\mathrm{t}}-\mathrm{W}_{\mathrm{o}}\right)}{\mathrm{W}_{\mathrm{o}}} \times 100
$$

Where,

$\mathrm{S}_{\mathrm{w}}=$ percentage of swelling of microbeads, $\mathrm{W}_{\mathrm{t}}=$ weight of the microbeads at time $t$, and $W_{0}=$ initial weight of the microbeads.

\section{In-vitro wash-off test for microbeads}

The mucoadhesive strength property of the cross-linked alginate microbeads was determined by conducting in vitro wash-off test. For doing of this test, few modifications were done to the disintegration test apparatus test. This test should be mimic same body atmospheric physiology conditions and for this reason, two freshly prepared buffer medium were used. During procedure acidic solution of $0.1 \mathrm{~N} \mathrm{HCl}$ was used for $8 \mathrm{~h}$ and this acid solution replaced fast with 6.8 phosphate buffer solution and same continued for another $8 \mathrm{~h}$. The important step involved in this test is use of fresh goat mucous membrane which surround the intestine of $3 \mathrm{~cm} \times 3 \mathrm{~cm}$ was rounded paddle completely at down place and keep and spread 100 fluvastatin microbeads exactly over mucous specimen and this paddle was connected to horizontal iron rod, which is clung to shaft of disintegration test apparatus (USP model) in the right position. During continuous up and down movement of shaft which is connected to the paddle that holds microbeads on mucous membrane and glass beakers contain acidic medium of $900 \mathrm{ml}$ capacity for the first $8 \mathrm{~h}$ and the apparatus run under the temperature of $37 \pm 0.5^{\circ} \mathrm{C}$ and movement of paddle up and down were maintained $60 \mathrm{rpm}$ without fail. The microbeads which are having maximum adhesive strength will stick long time to mucous membrane and not having mucoadhesive strength means, the beads will get detached in between study planned for $8 \mathrm{~h}$. The results of in vitro wash-off test of three batches are shown in Table 2.

\section{Dissolution studies}

To simulate the release of drug in both the human stomach and intestine atmosphere, in vitro studies were carried out under both acidic medium ( $\mathrm{pH} \mathrm{1.2)} \mathrm{for} \mathrm{the} \mathrm{first} 2 \mathrm{~h}$ and alkaline $\mathrm{pH} 6.8$ phosphate buffer) conditions as well as separately for next $10 \mathrm{~h}$ using dissolution test apparatus USP model. Dried fluvastatin microbeads were precisely weighed equivalent to $40 \mathrm{mg}$ and transferred into the dissolution basket

\begin{tabular}{|c|c|c|c|c|c|c|c|c|c|c|}
\hline \multirow[t]{3}{*}{ Formulation } & \multicolumn{10}{|c|}{ Percent of alginate beads adhering to tissue at 5 times (h) } \\
\hline & \multicolumn{5}{|c|}{$0.1 \mathrm{~N} \mathrm{HCl}, \mathrm{pH} 1.2$} & \multicolumn{5}{|c|}{ Phosphate buffer, pH 6.8} \\
\hline & 1 & 2 & 4 & 6 & 8 & 1 & 2 & 4 & 6 & 8 \\
\hline FSF8 & $68(1.5)$ & $57(1.8)$ & $47(1.2)$ & $38(1.8)$ & $26(2.0)$ & $94(0.5)$ & $87(1.0)$ & $79(1.0)$ & $66(1.0)$ & $57(1.0)$ \\
\hline FSF17 & $66(1.0)$ & $54(1.8)$ & $40(1.1)$ & $32(1.5)$ & $22(1.0)$ & $92(0.5)$ & $85(1.0)$ & $76(1.2)$ & $64(1.8)$ & $53(1.2)$ \\
\hline FSF18 & $62(1.8)$ & $50(1.2)$ & 38 (1.8) & $24(2.0)$ & $16(1.8)$ & $91(0.5)$ & $80(1.0)$ & $71(1.5)$ & 59 (1.5) & $47(2.0)$ \\
\hline $\begin{array}{l}\text { Microbeads } \\
\text { prepared with EVA }\end{array}$ & $48(1.2)$ & $22(1.4)$ & $4(1.0)$ & - & - & $42(0.5)$ & $18(1.6)$ & $2(0.2)$ & - & - \\
\hline
\end{tabular}

Table 2: In vitro wash-off test values for the fluvastatin sodium alginate microbeads prepared with combination of sodium alginate and HPMC K4M in 1:3 ratios by employing various cross-linking agents

*Each reading was taken in triplicate, i.e., $n=3$, Mean \pm SD. EVA: Ethyl vinyl acetate, HPMC: Hydroxypropyl methylcellulose 
which composed of $900 \mathrm{ml}$ freshly prepared dissolution mediums and paddle was rotated at $100 \mathrm{rpm}$ under a temperature of $37 \pm 0.5^{\circ} \mathrm{C}$. The dissolution medium containing drug released was sampled at various intervals of time up to $12 \mathrm{~h}$ by withdrawing sample hourly wise and then removed medium taking for sampling purposes and it was replaced by a fresh buffered medium with a similar quantity. The collected fluid was subjected to filtration by utilizing $0.22 \mu \mathrm{m}$ filter paper, aliquots of filtrate were diluted suitably [7-9] and the absorbance reading of fluid was taken out using an UV-visible spectrophotometer by fixing the wavelength working at $304 \mathrm{~nm}$. At last, the fluvastatin concentration was determined from the fluid using standardized calibration curve.

\section{Kinetic studies}

To evaluate the mechanism of drug discharge from the matrix tablets, the information got from the drug discharge studies was examined by the accompanying conditions. In all mathematical equations, $Q$ is the measure of medication discharged at time $t, M_{t}$ is the drug discharged at time $\mathrm{t}, \mathrm{M}$ is the total measure of medication in the dosage form, $\mathrm{F}$ is the portion of the medication discharged at time $t, \mathrm{~K}_{0}$ is the zero-order release rate constant, and " $\mathrm{n}$ " is the diffusion exponent type which demonstrating the mechanism of drug release. The value of $n=0.45$ demonstrates Fickian type dispersion, the estimation of $n$ somewhere in the range of $0.45-0.89$ indicates anomalous transport and the value $\mathrm{n}=0.89$ demonstrates Case-II transport model.

\section{RESULTS AND DISCUSSION}

On observation of micromeritic studies of alginate microbeads appeared as white, nearly spherical shape like and free-flowing of fluvastatin sodium microbeads were produced using the emulsification internal gelation method. The percentage yield varied from $91.68 \%$ to $98.32 \%$, with the highest yield obtained for FSF12 batch. The results show that increase in concentration of polymer blend ratio improves product yield, i.e., concentration of polymer blend was forms direct proportional. However, mean particle size has been shown to be increased with increasing polymer blend concentration, which could be due to enhancement in relative viscosities of polymer. The flow property parameter values are mentioned in Table 1, the angles of repose were found in the range of $20.39 \pm 0.05-$ $28.26 \pm 0.06$ (IP limits 25-30) showing that the blend of powder was freely flowing. The values for the Carr's index were between $12.32 \pm 0.04 \%$ and $15.87 \pm 0.06 \%$ (IP limits 11-15\%) indicating that all fluvastatin batches of powder blends were having good compressibility values. The Hausner's ratio was within the limits of 1.16 $\pm 0.012-1.22 \pm 0.05$ (IP limits 1.12-1.10). The results showed that all the batches showed good flow (rheological properties). The values of both tapped and bulk densities have shown good packing ability. The statistical data which is relavant to micromeritics of total formulations were shown in Table 3.

\section{Effect of core:coat ratio on drug entrapment}

In current article, a total of 18 batches have formulated and in all batches same quantity of drug was maintained and first four batches were designed only with combinations of drug and sodium alginate polymer (FSF1 to FSF4) was added. With different concentrations of sodium alginate ranging from $1 \%, 1.5 \%, 2 \%$, to $3 \% \mathrm{w} / \mathrm{v}$ along with drug, DEE will be enhanced the reason for progressive increment in the first four batches due to the availability of abundant number of crosslinking sites along polymer chains and it will drag more drug inside and maximum cross-linking taking place.

\section{Entrapment efficiency}

The percentage entrapment efficiency values for the first four batches ranged from $89.92 \pm 0.09 \%$ to $97.84 \pm 0.07 \%$. Hence, based on above evidence, it was proved that with increase in the concentration of polymers, i.e., polymer blend an increase in the drug entrapment efficiency of the microbeads was observed. It also depends on type of crosslinker used. In current studies, the three different cross-linking agents naming $\mathrm{AlCl}_{3}, \mathrm{BaCl}_{2}$, and $\mathrm{CaCl}_{2}$ at $5 \% \mathrm{w} / \mathrm{v}$ level were used along with polymer blend as per described procedure. In above three curing agents, the different batches and $\mathrm{AlCl}_{3}$ which is used as curing agent from FSF1 to FSF16 batches only will show maximum entrapment efficiency $97.84 \pm 0.07 \%$ because of it will form tight compact microbeads and not allow any leakage of drug during process of homogenization, microbeads obtained with $\mathrm{BaCl}_{2}$ (FSF17 batch) show less DEE than FSF8 batch The entrapment efficiencies were generally higher for the formulations that cross-linked with $\mathrm{Al}^{3+}$ and $\mathrm{Ca}^{2+}$ as compared to the microbeads cross-linked with $\mathrm{BaCl}_{2} 93.08 \pm 0.07 \%$ at the same concentrations of curing agents.

\section{FTIR studies}

The FTIR spectrum of pure fluvastatin sodium showed that characteristic peaks at wave numbers were $1013.16 \mathrm{~cm}^{-1}, 3688.12 \mathrm{~cm}^{-1}, 1214.96 \mathrm{~cm}^{-1}$, and $1481.32 \mathrm{~cm}^{-1}$ denoting stretching vibration of $\mathrm{C}-\mathrm{F}$ stretching, $\mathrm{O}-\mathrm{H}$ stretching, C-O stretching, and $\mathrm{CH}_{3}$ deformations, the peak at $949.56 \mathrm{~cm}^{-1}$ occurs due to aryl-F functional group, $1013.76 \mathrm{~cm}^{-1}$ due to stretching vibration of C-F type, $949.56 \mathrm{~cm}^{-1}$ corresponds to aryl-F, $1053.89 \mathrm{~cm}^{-1}$ due to $\mathrm{C}-\mathrm{F}$ stretching type, $1154.47 \mathrm{~cm}^{-1}$ due to ether stretching, $1215 \mathrm{~cm}^{-1}$ represents amine (C-N) group, $1481.32 \mathrm{~cm}^{-1} \mathrm{due}$ to $\mathrm{CH}_{3}$ deformation, $1579.87 \mathrm{~cm}^{-1}$ due to $\mathrm{C}=0$ stretching, $1620.28 \mathrm{~cm}^{-1}$ due to the presence of carboxyl stretch $\mathrm{C}=0,3375.41 \mathrm{~cm}^{-1}$ due to aryl-H, $3580.60 \mathrm{~cm}^{-1}$ due to $\mathrm{C}=\mathrm{O}$ stretching, $3688.12 \mathrm{~cm}^{-1}$ due to $\mathrm{O}-\mathrm{H}$ stretching type, and $3894.24 \mathrm{~cm}^{-1}$ due to $\mathrm{O}-\mathrm{H}$ bending, respectively. The FTIR spectrum (Figs. 1-5) of optimized formulation showed that characteristic peaks at wave numbers were $1009.53 \mathrm{~cm}^{-1}, 3028.37 \mathrm{~cm}^{-1}$ indicates $\mathrm{C}-\mathrm{H}$ fetching, $3644.11 \mathrm{~cm}^{-1}, 1214.67 \mathrm{~cm}^{-1}$, and $1480.31 \mathrm{~cm}^{-1}$ denoting stretching vibration of $\mathrm{C}-\mathrm{N}$ stretching, $\mathrm{O}-\mathrm{H}$ stretching, C-O

Table 3: Flow properties of fluvastatin-based sodium alginate microbeads

\begin{tabular}{|c|c|c|c|c|c|}
\hline Formulation & Angle of repose $(\theta)$ & Bulk density $\left(\mathrm{g} / \mathrm{cm}^{3}\right)$ & Tapped density $\left(\mathrm{g} / \mathrm{cm}^{3}\right)$ & Carr's index (\%) & Hausner's ratio \\
\hline FSF1 & $27.64 \pm 0.04$ & $0.867 \pm 0.08$ & $1.057 \pm 0.06$ & $15.06 \pm 0.04$ & $1.20 \pm 0.03$ \\
\hline FSF2 & $25.73 \pm 0.06$ & $0.886 \pm 0.04$ & $1.063 \pm 0.04$ & $14.18 \pm 0.02$ & $1.20 \pm 0.06$ \\
\hline FSF3 & $23.44 \pm 0.07$ & $0.897 \pm 0.03$ & $1.058 \pm 0.07$ & $13.13 \pm 0.06$ & $1.18 \pm 0.04$ \\
\hline FSF4 & $20.39 \pm 0.05$ & $0.913 \pm 0.07$ & $1.059 \pm 0.02$ & $12.32 \pm 0.04$ & $1.16 \pm 0.07$ \\
\hline FSF5 & $26.52 \pm 0.05$ & $0.514 \pm 0.06$ & $0.611 \pm 0.09$ & $15.17 \pm 0.06$ & $1.188 \pm 0.05$ \\
\hline FSF6 & $26.14 \pm 0.07$ & $0.522 \pm 0.05$ & $0.619 \pm 0.08$ & $15.087 \pm 0.05$ & $1.185 \pm 0.05$ \\
\hline FSF7 & $25.73 \pm 0.03$ & $0.524 \pm 0.09$ & $0.620 \pm 0.07$ & $15.48 \pm 0.04$ & $1.183 \pm 0.08$ \\
\hline FSF9 & $27.64 \pm 0.03$ & $0.514 \pm 0.02$ & $0.611 \pm 0.085$ & $14.87 \pm 0.07$ & $1.188 \pm 0.06$ \\
\hline FSF10 & $26.93 \pm 0.05$ & $0.519 \pm 0.05$ & $0.614 \pm 0.05$ & $15.10 \pm 0.07$ & $1.183 \pm 0.08$ \\
\hline FSF11 & $26.10 \pm 0.07$ & $0.521 \pm 0.06$ & $0.616 \pm 0.07$ & $15.42 \pm 0.03$ & $1.182 \pm 0.07$ \\
\hline FSF12 & $26.75 \pm 0.04$ & $0.531 \pm 0.08$ & $0.627 \pm 0.09$ & $15.31 \pm 0.05$ & $1.181 \pm 0.09$ \\
\hline FSF13 & $28.26 \pm 0.06$ & $0.783 \pm 0.04$ & $0.955 \pm 0.05$ & $15.72 \pm 0.07$ & $1.22 \pm 0.05$ \\
\hline FSF14 & $26.45 \pm 0.07$ & $0.799 \pm 0.05$ & $0.958 \pm 0.04$ & $14.36 \pm 0.05$ & $1.20 \pm 0.02$ \\
\hline FSF15 & $24.87 \pm 0.04$ & $0.914 \pm 0.02$ & $1.078 \pm 0.07$ & $13.74 \pm 0.06$ & $1.18 \pm 0.04$ \\
\hline FSF16 & $22.66 \pm 0.03$ & $0.928 \pm 0.08$ & $1.076 \pm 0.06$ & $12.71 \pm 0.04$ & $1.16 \pm 0.03$ \\
\hline FSF18 & $25.22 \pm 0.13$ & $0.445 \pm 0.009$ & $0.522 \pm 0.012$ & $13.94 \pm 0.03$ & $1.17 \pm 0.09$ \\
\hline
\end{tabular}

*All readings were taken in triplicate $(n=3)$. $S D+$ Mean 
stretching, and $\mathrm{CH}_{3}$ deformations, $1561.69 \mathrm{~cm}^{-1}$ indicating $\mathrm{C}=\mathrm{C}$, and $1692.98 \mathrm{~cm}^{-1}$ corresponding to $\mathrm{C}=0$, respectively. FTIR spectra of the physical mixture, i.e., optimized batch show almost nearest frequency range and near similar to the corresponding concurrent absorption of both the fluvastatin and added polymer molecules in same region of the FTIR spectra. Based on above evidence, the FTIR spectra of optimized batch depicted that there were no chances of any significant changes in the peak of fluvastatin sodium, as in making comparison of individual peaks as shown in pure fluvastatin (Fig. 1). The band at $3456 \mathrm{~cm}^{-1}$ is attributed to hydroxyl stretching in HPMC which was shifted to 3644.11 in optimized batch and also a peak at $1692.98 \mathrm{~cm}^{-1}$ which indicates the presence of $\mathrm{C}=0$ stretching in optimized batch, this clearly gives an idea about occurrence of acidic esterification between sodium alginate and HPMC. It is clearly suggesting that there were no physical or chemical interactions and there was no change in functional group of optimized batch, as shown in Fig. 5. From the Fig. 5, it was observed that similar peaks were also reported in optimized formulation, few of them listed here include. There was no marked change or large shifting of characteristic peaks in drug-loaded microbeads and which suggested that there were no significant drug-polymer interactions, which indicates the stable nature of the fluvastatin drug in optimized formulation. Frequency range of spectra of various polymers, drug and optimized are shown in Figs. 1-5.

\section{Morphology of microbeads}

The formed microbeads are somewhat resembles with spherical in shape, discrete and surface covered with wrinkled layer which might be indication for occurrence of egg-box model structure that cross-linked by G-guluronic acid in sodium alginate molecules with polymer blend and $\mathrm{AlCl}_{3}$.

The SEM photograph of fluvastatin sodium showed that microspheres were spherical in shape and also few microbeads posses surface are with smooth indicating uniform distribution of the drug in the polymeric matrix of the polymer. The SEM analysis also revealed that the prepared microbeads were found to devoid of aggregation microbeads and posses any kind of negligible surface charges this clearly indicating physical stability of microbeads. Significant effect was observed in shape of microbeads on increasing the equal concentration of polymer blend. The SEM of optimized microsphere formulation of fluvastatin sodium is shown in Fig. 6.

\section{DSC studies}

DSC studies were used to examine the crystallization and melting behaviors of pure drug and optimized batch. A sharp melting point at $120.89^{\circ} \mathrm{C}$ indicates its crystalline nature (Fig. 7). The temperature of the melting peak of fluvastatin in the microbeads, i.e., optimized batch

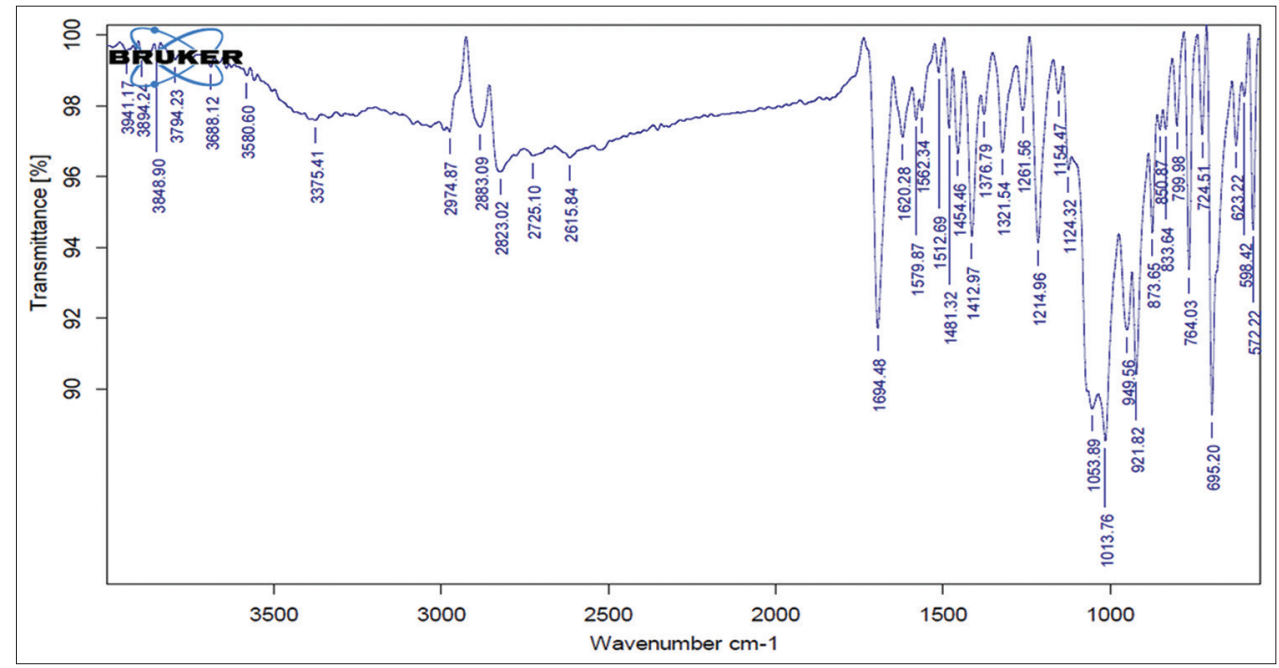

Fig. 1: Fourier transform infrared spectrum of pure fluvastatin sodium

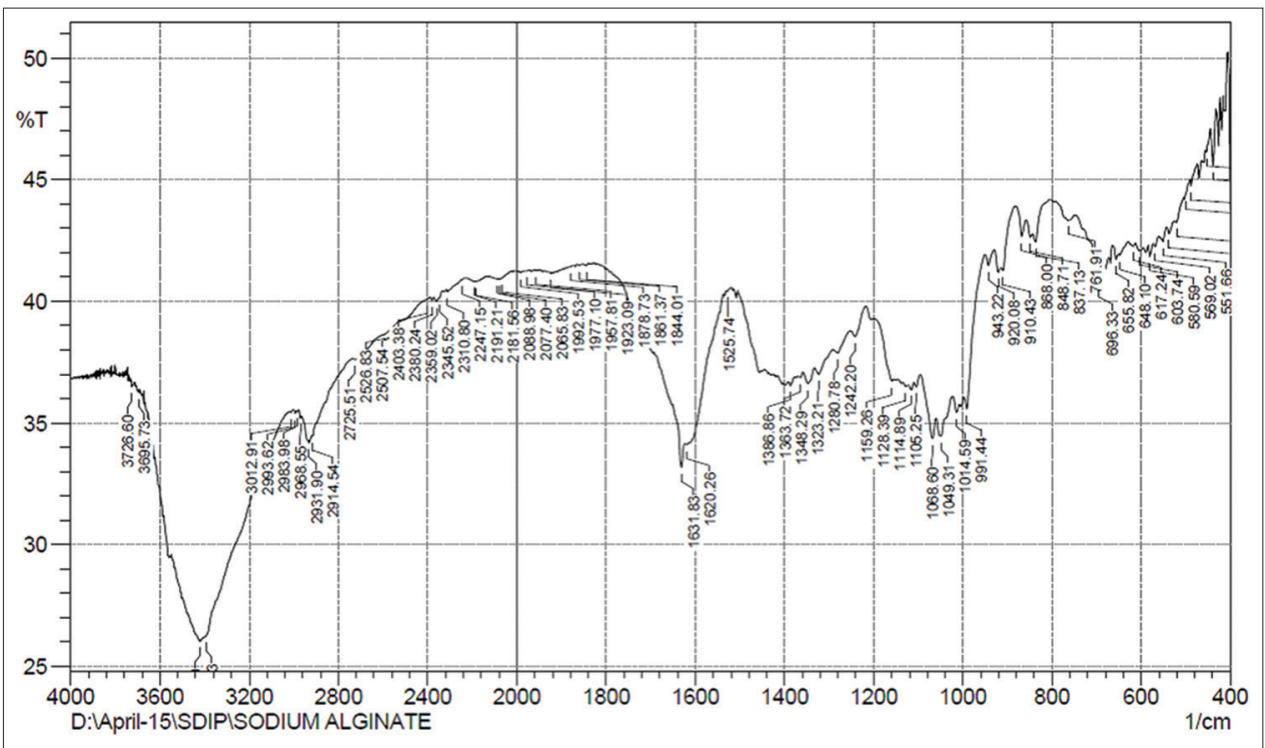

Fig. 2: Fourier transform infrared spectrum of pure sodium alginate 


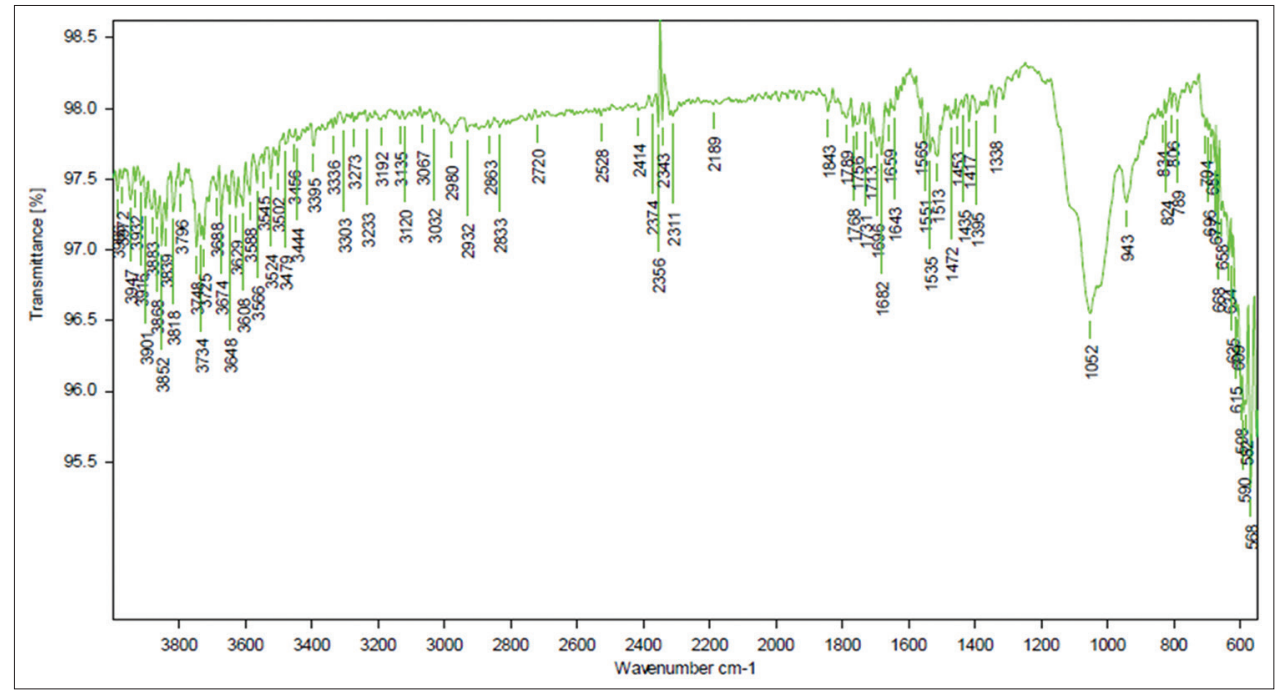

Fig. 3: Fourier transform infrared spectrum of pure hydroxypropyl methylcellulose K4M

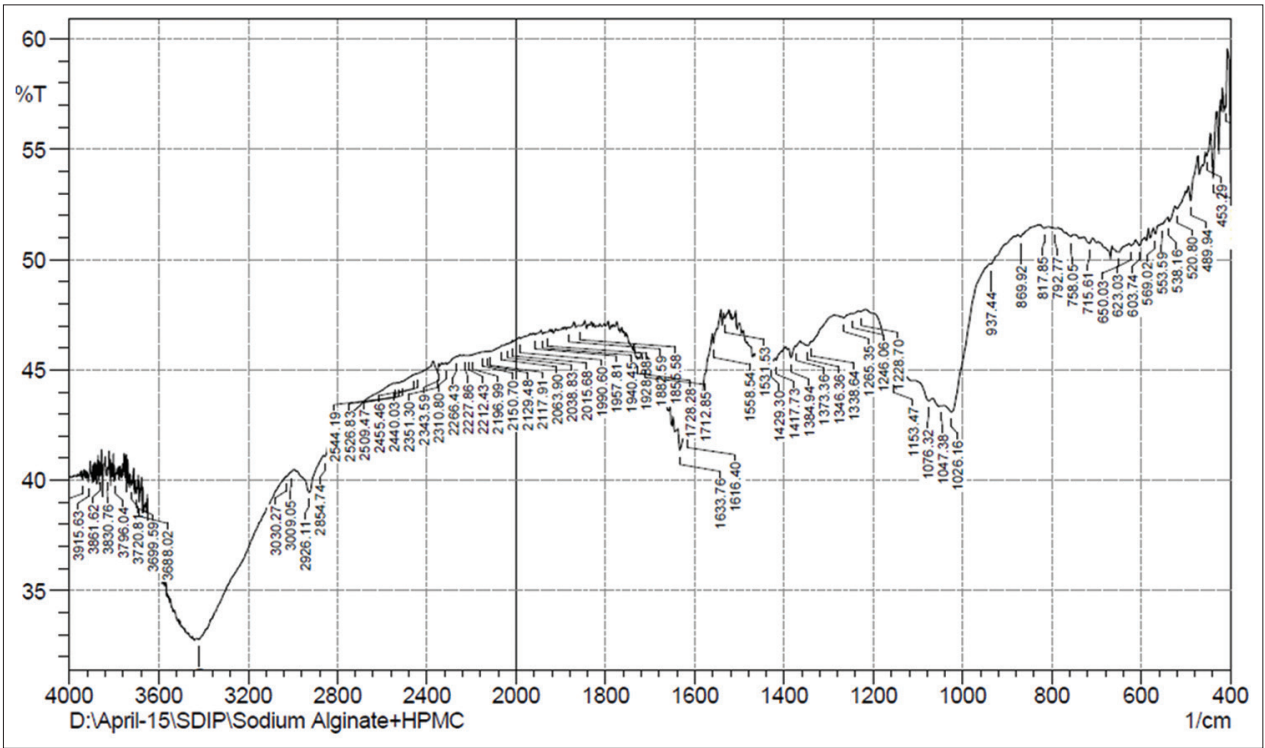

Fig. 4: Fourier transform infrared spectrum of physical mixture containing sodium alginate with hydroxypropyl methylcellulose K4M

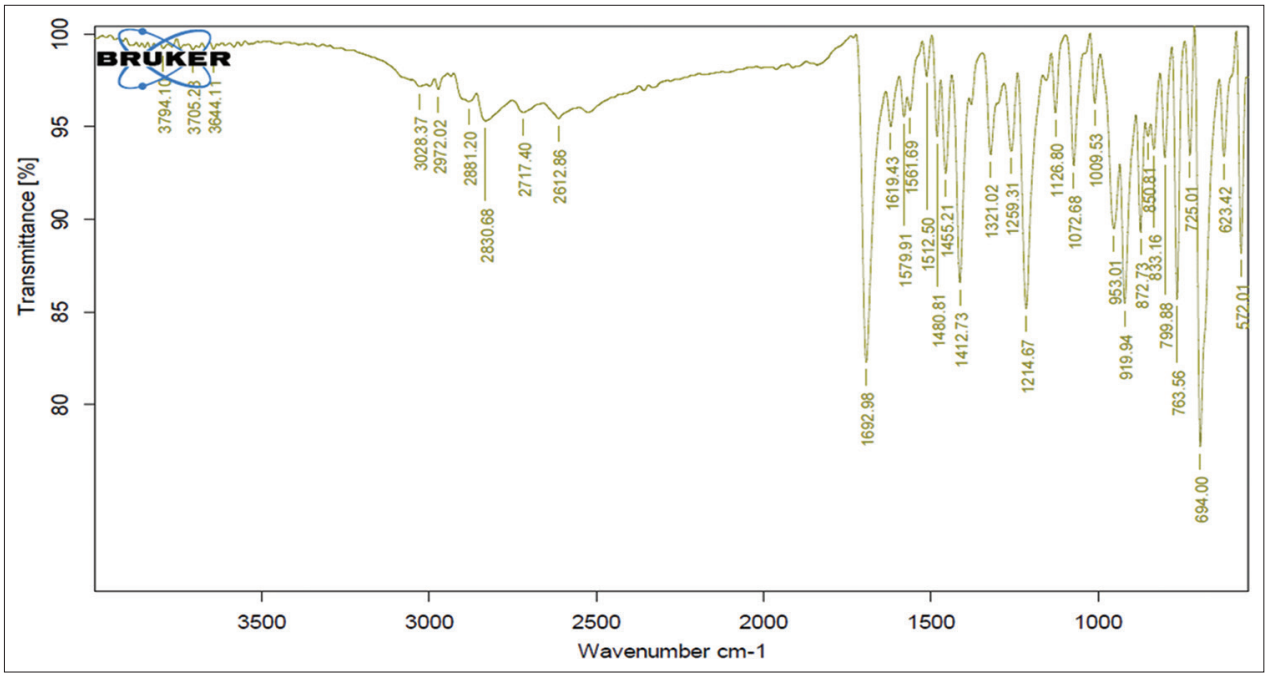

Fig. 5: Fourier transform infrared spectrum of optimized formulation 
FLF8 exhibited same a sharp endothermic peak as in pure drug at $114.35^{\circ} \mathrm{C}$ reflecting that near almost same temperature and other peaks at $178.11^{\circ} \mathrm{C}$ and $283.17^{\circ} \mathrm{C}$ indicates components were interacted each other while and evaporation of solvent on heating during the process. On examination of both DSC spectra of pure drug and optimization batch, the disappearance of endothermic peaks $\left(178.11^{\circ} \mathrm{C}\right)$ in optimized batch revealed and proves that fluvastatin exists in optimized batch (FLF8) in an uncrystallized form rather than exists in crystalline form as in pure drug and drug molecules have been distributed throughout polymer matrix bead and it also explained as the DSC thermogram of optimized fluvastatin batch does not show marked profound shifts in peaks in comparison to pure DSC spectra of fluvastatin indicating compatibility and thermographic results not showing any sign of reaction and existence of stability after the preparation.

\section{XRD properties}

The X-ray powder diffraction technique acts as powerful analytical tool in the identification of crystalline and non-crystalline phase. The characteristic diffraction peaks of fluvastatin sodium are at the
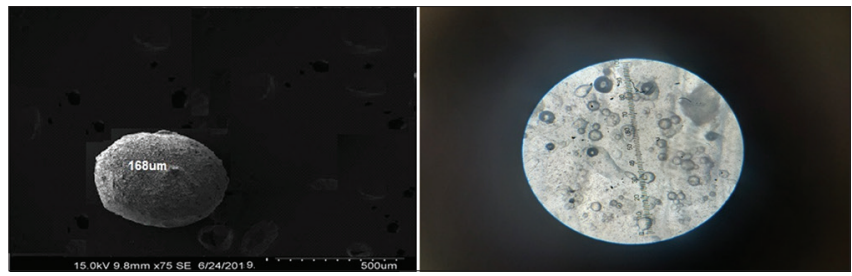

Fig. 6: Scanning electron microscope photograph of fluvastatin microbeads (left side) photographic image (right side) characteristics diffraction peaks of fluvastatin are at $(2 \theta) 11.1311^{\circ}$, $11.9581^{\circ}, 12.8641^{\circ}, 13.9792^{\circ}, 15.552^{\circ}, 16.455^{\circ}, 17.3989^{\circ}, 18.6393^{\circ}$, $19.6992^{\circ}, 20.6741^{\circ}, 21.5800^{\circ}, 22.3000^{\circ}, 23.8534^{\circ}, 24.6427^{\circ}, 25.6400^{\circ}$, $26.0836^{\circ}, 26.6400^{\circ}, 28.1321^{\circ}, 30.3000^{\circ}, 31.9000^{\circ}, 32.3200^{\circ}, 33.8940^{\circ}$, $34.9600^{\circ}, 35.5000^{\circ}, 36.4200^{\circ}, 37.0000^{\circ}, 38.9920^{\circ}, 41.0975^{\circ}, 42.1366^{\circ}$, $42.1366^{\circ}, 42.8481^{\circ}$, and $44.4573^{\circ}$ indicates the crystalline nature of the drug. Moreover, peaks of individual fluvastatin drug were still detectable in their respective optimized formulation with dramatically maximum reduction in intensity of peaks, and in optimized batch the much diffused pattern manner was observed in FSF8 batch which gives clear indication of conversion of crystalline state to the amorphous nature of drug. Thus, there is no indication of any interaction were identified in optimized formulation under the standard conditions. The $\mathrm{X}$-ray powder diffraction studies of fluvastatin sodium and optimized batch are shown in Fig. 8.

\section{Wash-off studies}

The microbeads consisting of sodium alginate alone and in combination with HPMC K4M, exhibited good mucoadhesive properties as observed in in vitro wash-off test when compared to microbeads prepared with non-mucoadhesive polymer ethyl vinyl acetate (EVA). The wash off was slow in the case of microbeads consisting of alginate-mucoadhesive polymers (hydrophilic nature) when compared to that of ethyl cellulose microspheres (Table 3). The wash off was faster at simulated intestinal $\mathrm{pH}$ (phosphate buffer 6.8) than comparison to that at simulated gastric $\mathrm{pH}$ (1.2). Swelling of the study depends on that the solubility, hydration, and mucoadhesivity of the polymers depend on the $\mathrm{pH}$ of the medium used. The rapid wash-off observed at simulated intestinal $\mathrm{pH}$ may be due to the ionization of carboxyl acid group in sodium alginate polymer and other functional groups present in the polymers, which increase

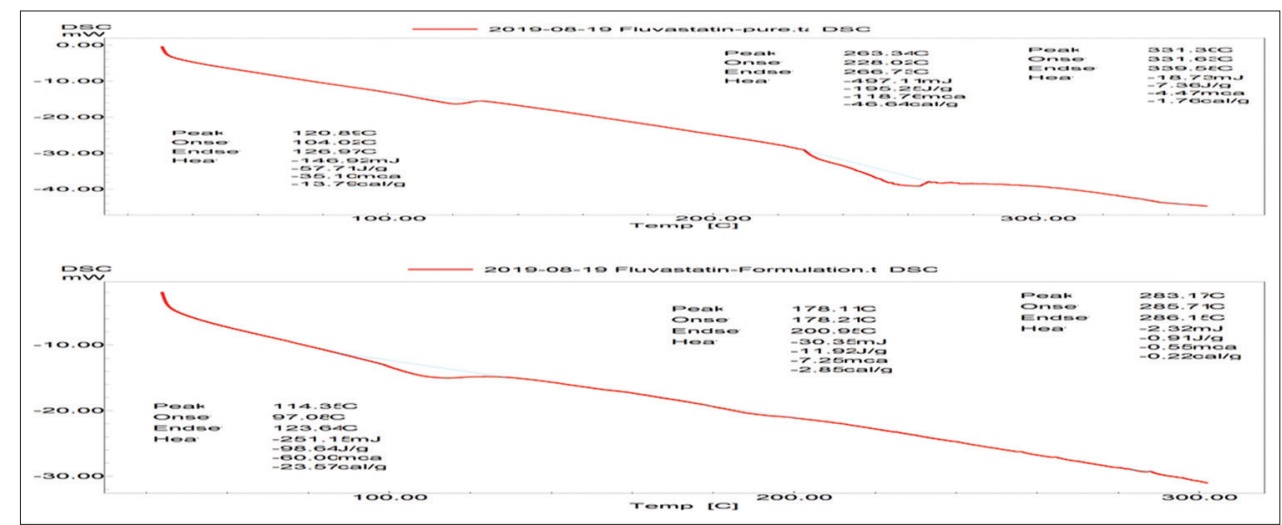

Fig. 7: Differential scanning calorimetry thermogram of pure fluvastatin (above spectra) and optimized batch (below spectra)

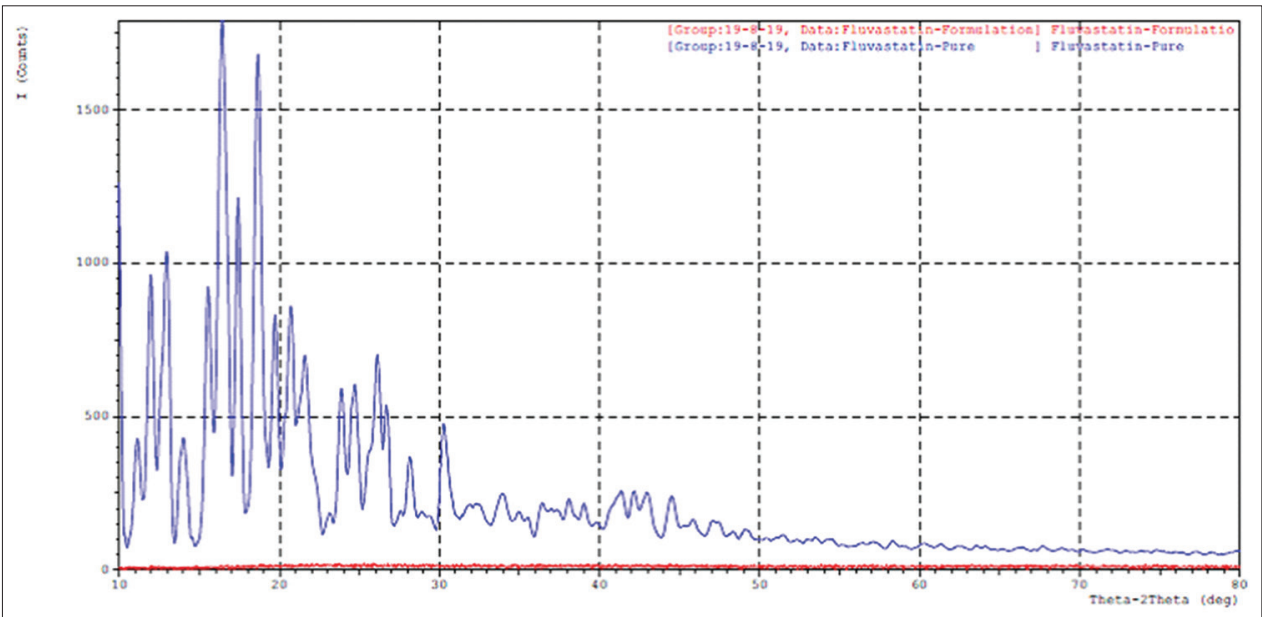

Fig. 8: X-ray diffraction spectra of pure fluvastatin drug (above spectra) and optimized batch (below spectra) 
their solubility and reduce adhesive strength. The mucoadhesive behaviors of various microbeads formulations are shown in Fig. 9. The developed mucoadhesive microbeads would adhere strongly because of high viscosity of polymer blend, maximum swelling of microbeads in alkaline medium than acidic medium and thereby to enhance the surface area of microbeads to the gastrointestinal mucous walls and also cause high relaxation of polymers chains and resisting gastric emptying time. This would cause to ensure the prolong residence time at the mucous absorption site to promote further intimate contact with the absorption surface and thereby to enhance the rate of bioavailability of drug.

\section{Determination of swelling index}

It was determined by studying in two different dissolution media naming $[10,11] \cdot 0.1 \mathrm{~N} \mathrm{HCl}$ for the first $2 \mathrm{~h}$ and later the previous medium was replaced with 6.8 phosphate buffer medium under temperature at $37 \pm 0.5^{\circ} \mathrm{C}$ with $100 \mathrm{rpm}$ and this test will be continued for $8 \mathrm{~h}$ with non-stop procedure using dissolution test apparatus USP model and basket (not paddle type) is used to hold microbeads inside which was ready to examine the swelling index. The measurement of swelling

Table 4: Swelling index values of fluvastatin sodium alginate microbeads prepared with a combination of sodium alginate and HPMC K4M in 1.5:1.5 ratio by employing various cross-linking agents

\begin{tabular}{llll}
\hline Formulation code & \multicolumn{3}{l}{ Swelling index } \\
\cline { 2 - 4 } & \multicolumn{2}{l}{ Time $\mathbf{~ h ) ~}$} & \\
\cline { 2 - 4 } & After $\mathbf{1} \mathbf{h}$ & After $\mathbf{2} \mathbf{~ h}$ & After $\mathbf{8 h}$ \\
\hline FSF8 & 23.45 & 33.82 & 75.20 \\
FSF17 & 26.72 & 49.44 & 89.68 \\
FSF18 & 30.67 & 57.13 & 97.47 \\
\hline
\end{tabular}

*Each reading taken in triplicate manner, i.e., $\mathrm{n}=3$. HPMC: Hydroxypropyl methylcellulose

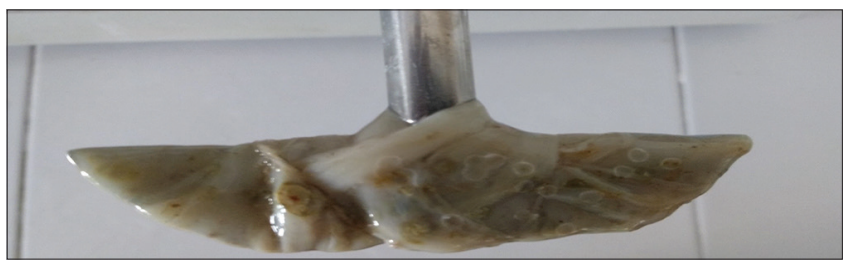

Fig. 9: Adherence of fluvastatin-based sodium alginate microbeads around mucous tissue specimen during wash-off test index of fluvastatin microbeads formulations using polymer blends of sodium alginate and HPMC K4M was carried out (FSF8 batch). This was conceptualized that high amount of polymer blend concentration, i.e., $3 \% \mathrm{w} / \mathrm{v}$ in equal proportions of sodium alginate and HPMC K4M absorbs huge quantity of solvent under alkaline conditions from the system in comparison to acidic medium and forms tight jelly like network around the surface of the microbeads with respect to the time $t$. This mechanical feature of surface hydrated polymer forms a viscous barricade that plays a major role in the whole amount of drug release rate. The swelling profiles for three different batches are shown in Fig. 9. However, interesting point in swelling rate after $8 \mathrm{~h}$ was observed in FSF8 batch than FSF17 and FSF18 that could be due to the reason of selection of different curing agents in above two different batches. In FSF8 batch been formulated using $5 \% \mathrm{w} / \mathrm{v}$ of $\mathrm{AlCl}_{3}$, as it forms three-dimensional network in cross-linking and forms very rigid surface microbeads which does not allow easily diffusion of solvent into the interior surface of the cross-linked beads, so in connection to this point the microbeads prepared with FSF8 formulation they will not undergoes maximum rate of swelling, i.e., less swelling $(75.20 \% / 8 \mathrm{~h})$ than other batches that designed with $\mathrm{BaCl}_{2}$ (FSF17) and $\mathrm{CaCl}_{2}$ (FSF18) at the same concentrations with same polymer blend (Table 4). The maximum rate of swelling 97.47\%/8 h was observed in FSF18 batch, which formulated with $\mathrm{CaCl}_{2}$ (divalency nature) and it allows easy diffusion of solvent into network of microbeads so that it leads to form maximum rate of swelling of all selected batches. The optimized batch containing HPMC K4M along with sodium alginate showed continuous increase in swelling. This may be again due to high proportion of polymeric system which retain water and form a thick swollen mass and minimize the erosion property of HPMC K4M (Fig. 10).

\section{Model dependent kinetics}

The drug release kinetics for all 18 batches was calculated using Microsoft Office Excel 2007 version. The release data were analyzed by fitting the profile of drug release of all the formulations into different kinetic orders which naming zero-order [12], first-order, Higuchi, and KorsmeyerPeppas model, and regression coefficients $\left(R^{2}\right)$ were calculated for all the formulations. The apparent dissolution rate constants $\mathrm{K}_{0}(\mathrm{mg} / \mathrm{h}), \mathrm{T}_{50(\mathrm{~h} .)}$ and $\mathrm{T}_{90(\mathrm{~h})}$. However, all batches posses maximum $\mathrm{R}^{2}$ value (Regression coefficient) ranging from 0.9771 to 0.998 indicates zero-order drug release and maximum diffusion exponent value " $n$ " 1.182 for optimized batch suggesting super Case-II transport mechanism.

The mechanism of fluvastatin based sodium alginate discharge from the hydrophilic matrix carrier system involves polymer swelling/erosion and non-Fickian diffusion of the drug. The parameters are shown in Table 5.

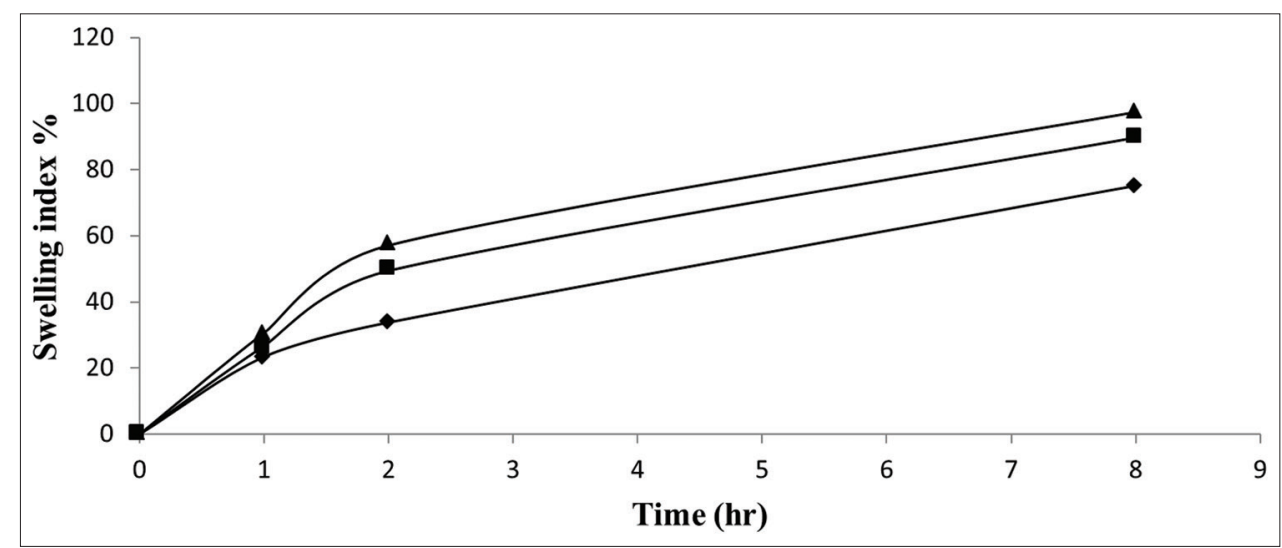

Fig. 10: Comparative swelling index plot of fluvastatin sodium alginate microbeads prepared with a combination of sodium alginate and hydroxypropyl methylcellulose K4M in 1:3 ratios by employing various types of cross-linking agents. FSF8 ( $~-)$ Fluvastatin sodium alginate microbeads prepared with a combination of sodium alginate and HPMC K4M in 1:3 ratio by employing aluminum chloride. FSF17(-m-) Fluvastatin sodium alginate microbeads prepared with a combination of sodium alginate and HPMC K4M in 1:3 ratio by employing barium chloride. FSF18(- $\Delta-$-) Fluvastatin sodium alginate microbeads prepared with a combination of sodium alginate and HPMC K4M in 1:3 ratio by employing calcium chloride. *Each reading taken in triplicate manner, i.e., $n=3$. 
Dissolution studies

The pattern could be controlled by the alginate gel disintegration in both $0.1 \mathrm{~N} \mathrm{HCl}$ acid for the first $2 \mathrm{~h}$ and continued the study up to $12 \mathrm{~h}$ by replacing previous medium freshly prepared 6.8 phosphate buffer solution at $37 \pm 0.5^{\circ} \mathrm{C}$ under $100 \mathrm{rpm}$ using paddle-type in vitro dissolution test apparatus. The breakdown or slow fragmentation of soft swellable alginate microbeads was monitored by the exchange of $\mathrm{Al}^{3+}$ from FSF1 to FSF8 batches with potassium ions present in the 6.8 potassium phosphate buffer dissolution medium. The drug release mainly relies on diffusion of drug through the small pores and cracks which are formed on surface of wet swellable microbeads during dissolution process under standard conditions.

The release behavior of alginate microbeads, produced by internal gelation with different gelling agents relies on the size and valence of the cations of the respective cross-linking agents at $5 \% \mathrm{w} / \mathrm{v}$. To investigate this mechanism, the polymer blend consists of sodium alginate $1.5 \%$ $\mathrm{w} / \mathrm{v}$ sodium alginate and $1.5 \% \mathrm{w} / \mathrm{v}$ of HPMC K4M were added with various cross-linking agents at $5 \% \mathrm{w} / \mathrm{v}$ concentrations naming $\mathrm{AlCl}^{3+}$ (FSF8 batch), $\mathrm{BaCl}^{2+}$ (FSF17), and $\mathrm{CaCl}^{2+}$ (FSF18) and their impact on drug release was studied.
The slow release of fluvastatin through the insoluble cross-linked matrix of blend polymer occurs in $0.1 \mathrm{~N} \mathrm{HCl}$ dissolution medium and very slow rate of swelling takes place in prepared microbeads and it results in only small quantity of drug release in acidic medium, in contrast to this, swelling and erosion of the microbeads prepared from polymer blend were highly observed in phosphate buffer of $\mathrm{pH}$ 6.8. Slow erosion of aluminum cross-linked fluvastatin based alginate microbeads could occur through slight degradation of sodium alginate backbone into smaller species.

The FLF8 batch in equal proportions of 1.5:1.5 containing polymer blend of sodium alginate and HPMC K4M retard or produces sustain the release of drug from the microbeads compared to other batches. The slow amount of drug release is due to swelling of HMPC K4M that makes in delays of drug release from the cross-linked microbeads. The drug release patterns of all eighteen batches are shown in Figs. 11-13. Due to the result of the rheology [13] of hydrated/swelled product, the swollen particles combine. This outcome in a non-stop viscoelastic matrix that fills the interstices, keeping the integrity of the microbeads, and hindering further entry of the dissolution medium into microbeads containing a higher amount $(1.5 \% \mathrm{w} / \mathrm{v})$ of HPMC K4M.

Table 5: In-vitro dissolution kinetics parameters of fluvastatin microbeads prepared with sodium alginate alone and in combination with hydroxypropyl methylcellulose $\mathrm{K} 4 \mathrm{M} / \mathrm{Carbopol} 934 \mathrm{P} / \mathrm{NaCMC}$ in different ratios by employing aluminum chloride/barium chloride/calcium chloride as a cross-linking agent at $5 \% \mathrm{w} / \mathrm{v}$

\begin{tabular}{|c|c|c|c|c|c|c|c|c|}
\hline \multirow[t]{2}{*}{ Formulation } & \multicolumn{4}{|c|}{ Correlation coefficient $\left(R^{2}\right)$} & \multicolumn{3}{|c|}{ Release kinetics } & \multirow[t]{2}{*}{ Diffusionexponent value(n) } \\
\hline & Zero order & First order & Higuchi & Peppas & $\mathrm{K}_{\mathrm{o}}(\mathrm{mg} / \mathrm{h})$ & $\mathrm{T5} \mathbf{0}_{0}(\mathrm{~h})$ & $T_{90}(h)$ & \\
\hline FSF1 & 0.9992 & 0.7245 & 0.8952 & 0.9902 & 5.17 & 3.86 & 6.96 & 0.8956 \\
\hline FSF3 & 0.9976 & 0.7683 & 0.9178 & 0.9946 & 4.41 & 4.53 & 8.16 & 0.8778 \\
\hline FSF4 & 0.9979 & 0.7709 & 0.9315 & 0.9968 & 3.56 & 5.61 & 10.11 & 0.8500 \\
\hline FSF5 & 0.9996 & 0.8056 & 0.9303 & 0.9990 & 4.72 & 4.23 & 7.62 & 0.9112 \\
\hline FSF6 & 0.9989 & 0.7971 & 0.9107 & 0.9998 & 4.4 & 4.5 & 8.18 & 1.082 \\
\hline FSF7 & 0.9986 & 0.8073 & 0.9214 & 0.9985 & 3.84 & 5.1 & 9.2 & 1.108 \\
\hline FSF8 & 0.9983 & 0.6380 & 0.9052 & 0.9991 & 3.28 & 6.09 & 10.97 & 1.182 \\
\hline FSF9 & 0.9976 & 0.7964 & 0.9404 & 0.9975 & 4.96 & 4.03 & 7.25 & 0.8418 \\
\hline FSF10 & 0.9998 & 0.8044 & 0.9268 & 0.9995 & 4.64 & 4.31 & 7.75 & 0.9427 \\
\hline FSF11 & 0.9994 & 0.8068 & 0.9228 & 0.9928 & 4.08 & 4.9 & 8.82 & 1.0301 \\
\hline FSF12 & 0.9998 & 0.7640 & 0.9261 & 0.9993 & 3.60 & 5.5 & 10.0 & 1.1035 \\
\hline FSF13 & 0.9778 & 0.7407 & 0.9089 & 0.9941 & 5.70 & 3.50 & 6.31 & 0.8883 \\
\hline FSF14 & 0.9771 & 0.7705 & 0.9167 & 0.9960 & 4.80 & 4.16 & 7.5 & 0.8802 \\
\hline FSF15 & 0.9910 & 0.7991 & 0.9278 & 0.9971 & 4.50 & 4.44 & 8.0 & 0.8748 \\
\hline FSF17 & 0.9990 & 0.7235 & 0.9126 & 0.9966 & 3.48 & 5.74 & 10.32 & 0.8801 \\
\hline FSF18 & 0.9976 & 0.7478 & 0.9168 & 0.9934 & 3.60 & 5.55 & 10.0 & 0.9023 \\
\hline
\end{tabular}

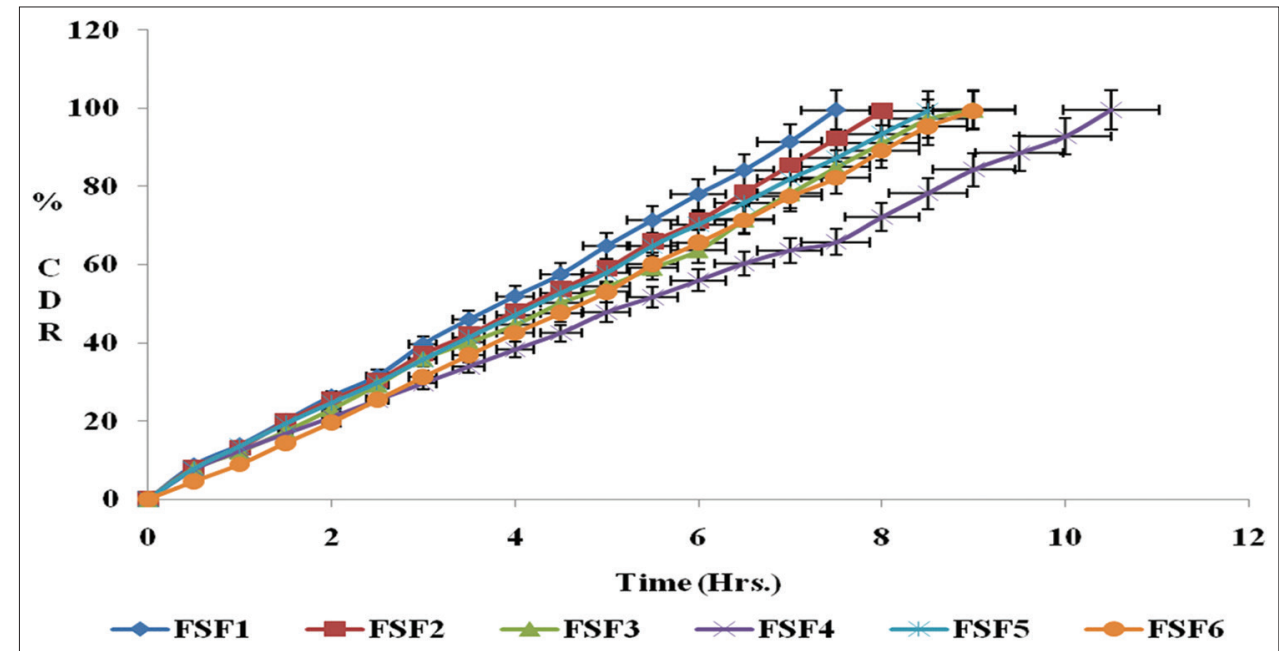

Fig. 11: Dissolution profile of batches from FSF1 to FSF6. Each value taken in triplicate, i.e., $n=3$. Mean \pm SD 


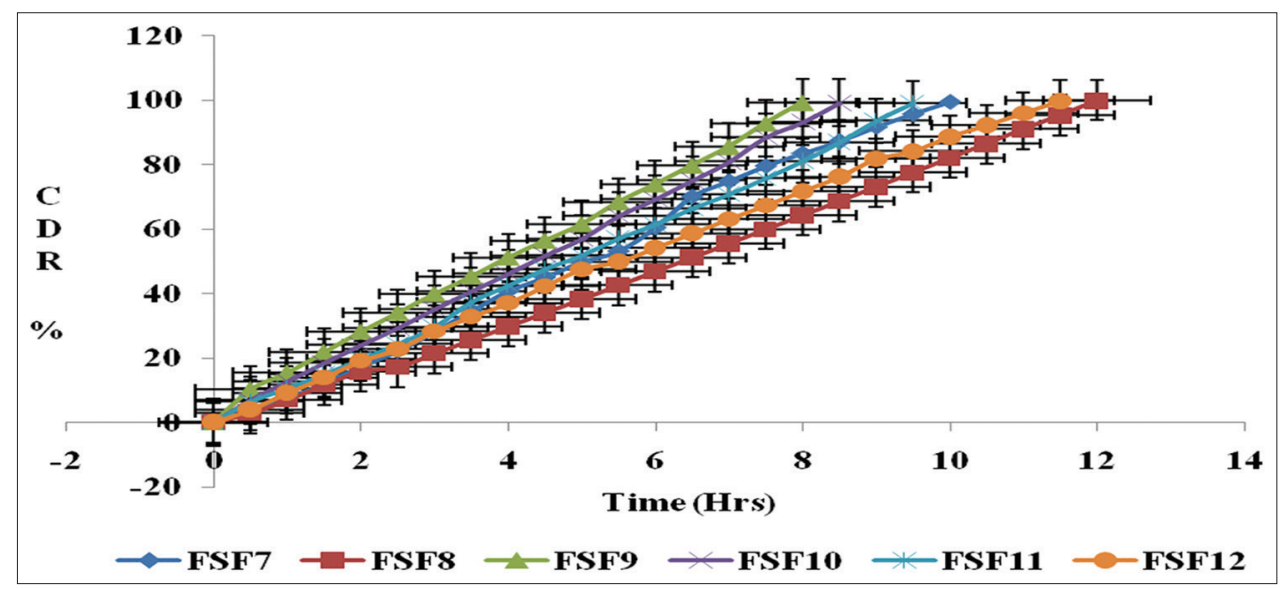

Fig. 12: Dissolution profile of batches from FSF7 to FSF12. Each value taken in triplicate, i.e., $n=3$. Mean \pm SD

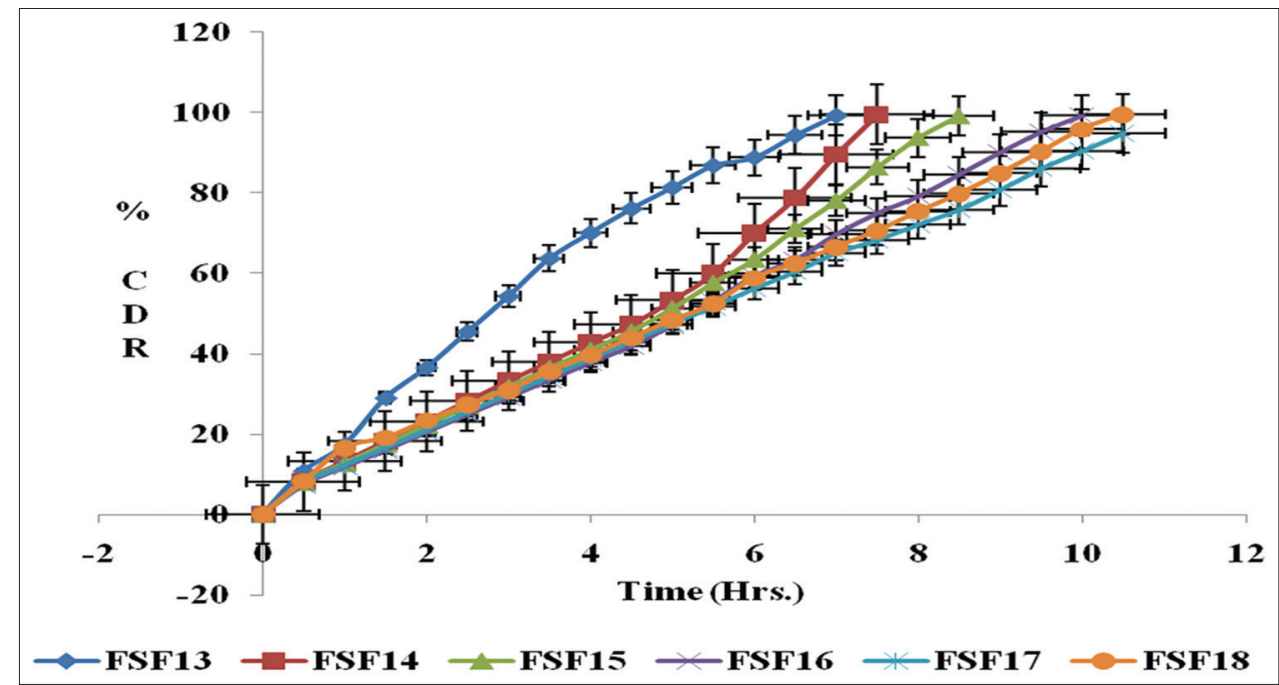

Fig. 13: Dissolution profile of batches from FSF13 to FSF18. Each value taken in triplicate, i.e., n=3. Mean \pm SD

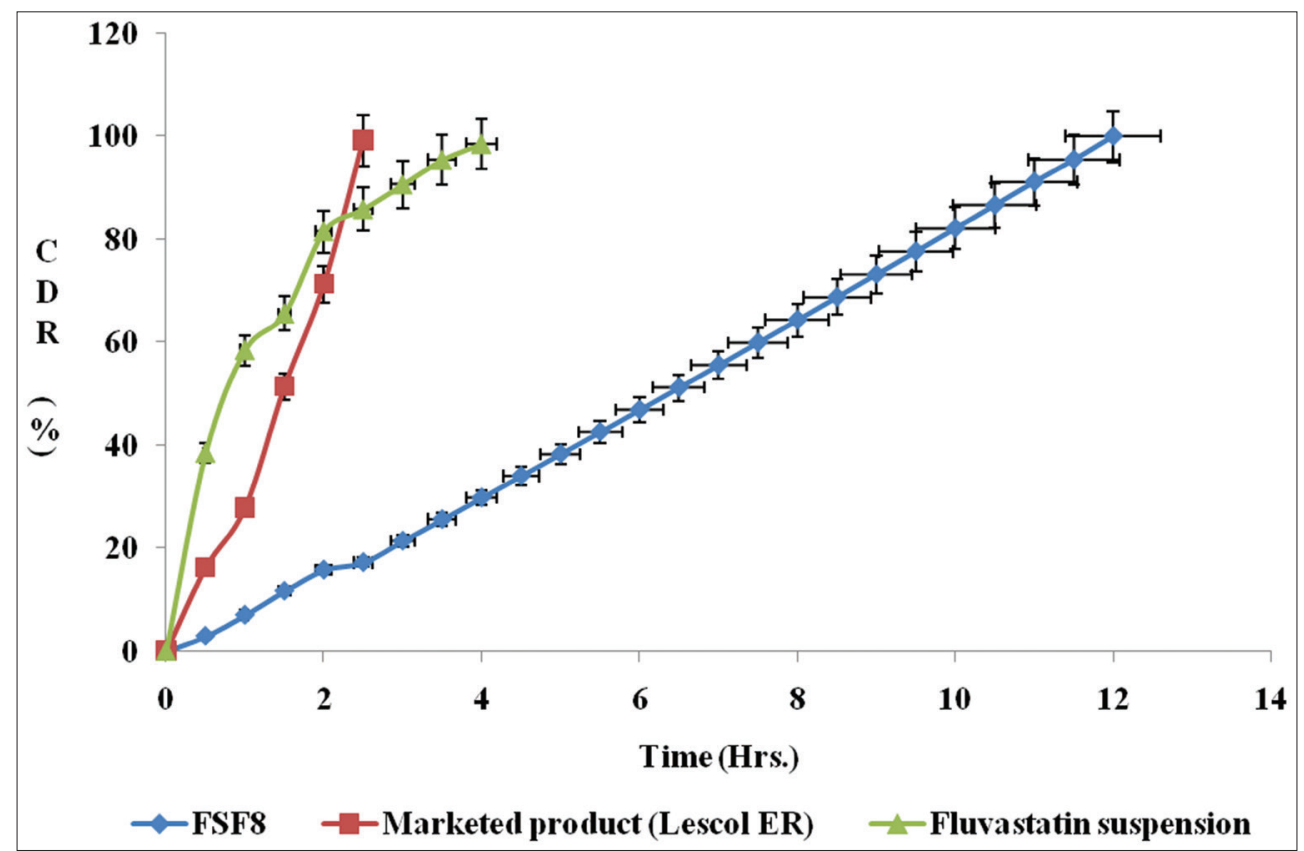

Fig. 14: Comparative dissolution profile of optimized batch FSF8, marketed product, and pure drug. Each value taken in triplicate, i.e., $n=3$. Mean \pm SD 
The outcomes acquired can be clarified on the basis of the extent of crosslinking in the microspheres. In case of $\mathrm{CaCl}_{2}$ and $\mathrm{BaCl}_{2}$ used as hardening agents in batches (FSF18 and FSF17) and of their divalence nature, they form two-dimensional network bonding structure with sodium alginate chain inside the cross-linked alginate matrices. In case of $\mathrm{Ba}^{2+}$ it has the largest size $\left(1.74 \mathrm{~A}^{\circ}\right)$ when compared to the other two curing agents $\left(0.68 \mathrm{~A}^{\circ}\right.$ for $\mathrm{Al}^{3+}$ and $1.14 \mathrm{~A}^{\circ}$ for $\left.\mathrm{Ca}^{2+}\right)$ it is expected to form strong alginate microspheres with little voids and minimum water uptake. Along these lines, the exchange of larger barium ions in the microbeads with potassium ions of dissolution medium (phosphate buffer, $\mathrm{pH}$ 6.8) and furthermore, their expulsion as insoluble barium phosphate was upset, and this resulting in delayed swelling rate of the microbeads and slow release of drug occurs. In case of calcium alginate microbeads, due to the smaller size of $\mathrm{Ca}^{2+}$ ions as compared to barium ions, it ensures fast removal of calcium as calcium phosphate from the microbeads due to process of ion exchange with potassium of 6.8 phosphate buffer medium and thus leading to greater amount of fluid uptake and this leads to cause maximum release of drug. In case of $\mathrm{Al}^{3+}$ alginate microbeads, this deferral was taken place and it was due to the ability of $\mathrm{Al}^{3+}$ to form three-dimensional bonding network bonding structure with the sodium alginate inside the microbeads. This three dimensional bonding results in an extended cross-linking through the whole microbeads, producing rigid and compact surface of cross-linked alginate microbeads with low amount of water uptake and it leading to slow removal of $\mathrm{Al}^{3+}$ due to ion exchange with potassium ions present in the 6.8 phosphate buffer medium. As a result, the swelling of the soft cross-linked beads is delayed and it leading to slow disintegration of microbeads.

The percent of drug release for FSF8 batch to reach $\mathrm{T}_{90}$ is $10.97 \mathrm{~h}$, towards FSF17 batch $10.32 \mathrm{~h}$ and for FSF18 batch it was took $10 \mathrm{~h}$. Hence, on the basis of above long discussion regarding drug release data, only FSF8 batch will provide SR up to $12 \mathrm{~h}$ and it leads to reduce the frequency of drug administration, so to minimize the incidence of side effects, thereby to improve patience compliance.

There is change observed on surface of the microbeads after dissolution experiment showed presence of microns size of pores which gives the indication that the fluvastatin drug was released occurs through these pores slowly by swelling and the mechanism of drug release was completely swelling and diffusion-controlled based. The diffusion

Table 6: Drug content, encapsulation efficiency, and dissolution kinetics of fluvastatin sodium alginate microbeads stored at $25 \pm 2{ }^{\circ} \mathrm{C} / 60 \pm 5 \% \mathrm{RH}$ and $40 \pm 2{ }^{\circ} \mathrm{C} / 75 \pm 5 \% \mathrm{RH}$

\begin{tabular}{|c|c|c|c|c|c|c|}
\hline Storage conditions & Time interval & Drugcontent & Encapsulationefficiency & Release rate constant(mg/h) $K_{0}$ & $\mathbf{t}_{50 \%}$ & $t_{90 \%}$ \\
\hline \multirow[t]{3}{*}{$25 \pm 2^{\circ} \mathrm{C} / 60 \pm 5 \% \mathrm{RH}$} & $1^{\text {st }}$ month & 24.40 & 97.60 & 3.28 & 6.09 & 10.97 \\
\hline & $2^{\text {nd }}$ month & 24.38 & 97.52 & 3.28 & 6.09 & 10.97 \\
\hline & $3^{\text {rd }}$ month & 24.35 & 97.40 & 3.28 & 6.09 & 10.97 \\
\hline \multirow[t]{3}{*}{$40 \pm 2^{\circ} \mathrm{C} / 75 \pm 5 \% \mathrm{RH}$} & $1^{\text {st }}$ month & 24.37 & 97.48 & 3.28 & 6.09 & 10.97 \\
\hline & $2^{\text {nd }}$ month & 24.34 & 97.36 & 3.28 & 6.09 & 10.97 \\
\hline & $3^{\text {rd }}$ month & 24.32 & 97.28 & 3.28 & 6.09 & 10.97 \\
\hline
\end{tabular}

*Each value taken in triplicate. $\mathrm{n}=3$

Table 7: In-vitro dissolution data of fluvastatin cross-linked sodium microbeads stored at $25 \pm 2{ }^{\circ} \mathrm{C} / 60 \pm 5 \% \mathrm{RH}$ and $40 \pm 2{ }^{\circ} \mathrm{C} / 75 \pm 5 \% \mathrm{RH}$ after 3 months stability studies

\begin{tabular}{|c|c|c|c|c|c|c|c|c|}
\hline \multirow[t]{3}{*}{ S.No. } & \multirow[t]{3}{*}{ Time (h) } & \multirow[t]{3}{*}{ Initial } & \multicolumn{6}{|c|}{ Percentage of fluvastatin sodium released $(\mathrm{X} \pm \mathrm{SD})$} \\
\hline & & & \multicolumn{3}{|c|}{$25 \pm 2^{\circ} \mathrm{C} / 60 \pm 5 \% \mathrm{RH}$} & \multicolumn{3}{|c|}{$40 \pm 2^{\circ} \mathrm{C} / 75 \pm 5 \% \mathrm{RH}$} \\
\hline & & & $1^{\text {st }}$ month & $2^{\text {nd }}$ month & $3^{\text {rd }}$ month & $1^{\text {st }}$ month & $2^{\text {nd }}$ month & $3^{\text {rd }}$ month \\
\hline 1. & 0 & 0 & 0 & 0 & 0 & 0 & 0 & 0 \\
\hline 2. & 0.5 & $2.94 \pm 0.15$ & $2.84 \pm 0.09$ & $2.76 \pm 0.13$ & $2.67 \pm 0.06$ & $2.72 \pm 0.13$ & $2.64 \pm 0.08$ & $2.55 \pm 0.05$ \\
\hline 3. & 1 & $7.02 \pm 0.08$ & $6.93 \pm 0.14$ & $6.86 \pm 0.06$ & $6.75 \pm 0.13$ & $6.81 \pm 0.11$ & $6.73 \pm 0.09$ & $6.66 \pm 0.08$ \\
\hline 4. & 1.5 & $11.68 \pm 0.15$ & $11.57 \pm 0.10$ & $11.48 \pm 0.08$ & $11.40 \pm 0.09$ & $11.45 \pm 0.14$ & $11.39 \pm 0.11$ & $11.13 \pm 0.05$ \\
\hline 5. & 2 & $15.81 \pm 0.11$ & $15.72 \pm 0.11$ & $15.64 \pm 0.05$ & $15.64 \pm 0.05$ & $15.57 \pm 0.06$ & $15.43 \pm 0.10$ & $15.36 \pm 0.11$ \\
\hline 6. & 2.5 & $17.25 \pm 0.06$ & $17.16 \pm 0.15$ & $17.07 \pm 0.09$ & $16.98 \pm 0.09$ & $17.06 \pm 0.05$ & $16.97 \pm 0.11$ & $16.85 \pm 0.10$ \\
\hline 7. & 3 & $21.42 \pm 0.11$ & $21.33 \pm 0.13$ & $21.26 \pm 0.11$ & $21.14 \pm 0.15$ & $21.19 \pm 0.13$ & $21.12 \pm 0.06$ & $21.04 \pm 0.13$ \\
\hline 8. & 3.5 & $25.61 \pm 0.09$ & $25.52 \pm 0.09$ & $25.43 \pm 0.13$ & $25.33 \pm 0.09$ & $25.39 \pm 0.09$ & $25.32 \pm 0.08$ & $25.25 \pm 0.11$ \\
\hline 9. & 4 & $29.82 \pm 0.11$ & $29.73 \pm 0.06$ & $29.64 \pm 0.15$ & $29.54 \pm 0.06$ & $29.59 \pm 0.15$ & $29.53 \pm 0.13$ & $29.46 \pm 0.09$ \\
\hline 10. & 4.5 & $34.05 \pm 0.08$ & $33.96 \pm 0.08$ & $33.87 \pm 0.06$ & $33.77 \pm 0.08$ & $33.82 \pm 0.13$ & $33.74 \pm 0.09$ & $33.65 \pm 0.08$ \\
\hline 11. & 5 & $38.31 \pm 0.06$ & $38.22 \pm 0.10$ & $38.13 \pm 0.09$ & $38.02 \pm 0.13$ & $38.09 \pm 0.10$ & $38.02 \pm 0.15$ & $37.94 \pm 0.06$ \\
\hline 12. & 5.5 & $42.58 \pm 0.11$ & $42.49 \pm 0.08$ & $42.40 \pm 0.05$ & $42.30 \pm 0.06$ & $42.37 \pm 0.05$ & $42.31 \pm 0.10$ & $42.27 \pm 0.09$ \\
\hline 13. & 6 & $46.88 \pm 0.06$ & $46.80 \pm 0.11$ & $40.71 \pm 0.06$ & $46.60 \pm 0.11$ & $46.66 \pm 0.11$ & $46.59 \pm 0.06$ & $46.43 \pm 0.11$ \\
\hline 14. & 6.5 & $51.21 \pm 0.15$ & $51.12 \pm 0.14$ & $51.03 \pm 0.05$ & $50.92 \pm 0.10$ & $50.98 \pm 0.13$ & $50.91 \pm 0.08$ & $50.83 \pm 0.10$ \\
\hline 15. & 7 & $55.55 \pm 0.09$ & $55.47 \pm 0.09$ & $55.39 \pm 0.11$ & $55.26 \pm 0.15$ & $55.32 \pm 0.05$ & $55.26 \pm 0.06$ & $54.97 \pm 0.13$ \\
\hline 16. & 7.5 & $59.92 \pm 0.15$ & $59.84 \pm 0.13$ & $59.76 \pm 0.08$ & $59.63 \pm 0.09$ & $59.69 \pm 0.15$ & $59.61 \pm 0.13$ & $59.54 \pm 0.15$ \\
\hline 17. & 8 & $64.31 \pm 0.08$ & $64.22 \pm 0.11$ & $64.13 \pm 0.10$ & $64.02 \pm 0.06$ & $64.09 \pm 0.09$ & $64.03 \pm 0.11$ & $63.94 \pm 0.10$ \\
\hline 18. & 8.5 & $68.73 \pm 0.11$ & $68.64 \pm 0.14$ & $68.54 \pm 0.13$ & $68.45 \pm 0.11$ & $68.51 \pm 0.06$ & $68.44 \pm 0.08$ & $68.37 \pm 0.11$ \\
\hline 19. & 9 & $73.16 \pm 0.06$ & $73.08 \pm 0.12$ & $72.99 \pm 0.09$ & $72.90 \pm 0.09$ & $72.99 \pm 0.08$ & $72.92 \pm 0.09$ & $72.57 \pm 0.13$ \\
\hline 20. & 9.5 & $77.62 \pm 0.15$ & $77.54 \pm 0.15$ & $77.43 \pm 0.06$ & $77.32 \pm 0.06$ & $77.37 \pm 0.09$ & $77.31 \pm 0.11$ & $77.43 \pm 0.15$ \\
\hline 21. & 10 & $82.1 \pm 0.09$ & $82.07 \pm 0.13$ & $81.91 \pm 0.08$ & $81.80 \pm 0.08$ & $81.86 \pm 0.05$ & $81.80 \pm 0.09$ & $81.73 \pm 0.09$ \\
\hline 22. & 10.5 & $86.61 \pm 0.11$ & $86.52 \pm 0.10$ & $86.44 \pm 0.15$ & $86.31 \pm 0.13$ & $86.38 \pm 0.06$ & $86.32 \pm 0.10$ & $86.26 \pm 0.10$ \\
\hline 23. & 11 & $91.13 \pm 0.08$ & $91.07 \pm 0.11$ & $90.95 \pm 0.10$ & $90.83 \pm 0.10$ & $90.89 \pm 0.10$ & $90.83 \pm 0.13$ & $90.76 \pm 0.13$ \\
\hline 24. & 11.5 & $95.41 \pm 0.09$ & $95.33 \pm 0.13$ & $95.25 \pm 0.09$ & $95.16 \pm 0.14$ & $95.21 \pm 0.15$ & $95.16 \pm 0.09$ & $95.08 \pm 0.15$ \\
\hline 25. & 12 & $99.98 \pm 0.12$ & $99.90 \pm 0.10$ & $99.82 \pm 0.11$ & $99.72 \pm 0.13$ & $99.79 \pm 0.09$ & $99.73 \pm 0.06$ & $99.66 \pm 0.08$ \\
\hline
\end{tabular}

*Each value taken in triplicaten $=3$. Mean \pm SD 
exponent " $\mathrm{n}$ " for optimized batch is 1.182 that indicates drug release follows super Case II transport mechanism controlled by both swelling and relaxation of the polymer chains. The drug release of optimized batch FSF8 were compared to pure drug and marketed tablet of same strength of drug to elucidate the difference and progress in achievement of controlled drug release of optimized batch. The drug release profile of pure drug, optimized batch, and marketed product (Lescol ER) is shown in Fig. 14. All readings were taken in triplicate, i.e., $n=3$.

\section{Stability studies}

The optimized formulation FSF8 was subjected to stability studies at both room temperature i.e., $28^{\circ} \mathrm{C}$ and $45^{\circ} \mathrm{C} / 75 \% \mathrm{RH}$ and evaluated for their drug content, DEE, release rate constant and in vitro drug release. Only small negligible changes were observed in the different physicochemical parameters at different temperatures, i.e., $28^{\circ} \mathrm{C}$ and $45^{\circ} \mathrm{C} / 75 \%$ RH which studied for 3 months under standard conditions and as per International Council for Harmonisation (ICH) guidelines (Tables 6 and 7). The details of in vitro data after stability studies done for 3 months at different temperature and humidity conditions are shown in Table 7, and details of drug content, entrapment efficiency, release rate constant, $t_{50 \%}$ and $t_{90 \%}$ with respect to monthly wise up to 3 months are shown in Table 6

\section{CONCLUSION}

Among all the formulations, fluvastatin loaded mucoadhesive microbeads prepared with sodium alginate and HPMC K4M (FSF8 batch) in equal proportion of 1.5:1.5 shows CR up to $12 \mathrm{~h}$. Effect of various factors such as concentration of polymer, combination of sodium alginate with other polymers, type of cross-linking agent effect, and concentration of polymer blend was studied. Using emulsification-internal gelation technique, it is possible to obtain a maximum drug entrapment efficiency of $97.84 \pm 0.07 \%$. It was clear that as the quantity of the polymer is increases, the rate of drug release is reduced and microbeads prepared with $\mathrm{AlCl}_{3}$ as a curing agent only provides $\mathrm{CR}$ of drug. The formed microbeads were spherical in shape and fluvastatin remained distributed in the polymer matrix at amorphous state which was proved by X-ray diffraction studies, it proves clearly that the rate of bioavailability of drug was enhanced. The prepared microspheres exhibited good mucoadhesive properties as observed in in vitro wash-off test when compared to a non-mucoadhesive polymer, EVA microbeads. The drug release mechanism was Case II transport kinetic model type which indicates drug release occurs by both swelling and relaxation of microbeads. There was no significant change in drug entrapment and drug release profile when stored at different storage atmospheric conditions as it is proved by conducting stability studies as per the ICH guidelines.

\section{AUTHORS' CONTRIBUTIONS}

The complete guidance of work, design of experiment, knowledge support, and help for the research work, experimental work, optimization and interpretation of analytical results was done by Mr. VenkataRamana Reddy K. Nagabhushanam MV and Sai Kishore V.

\section{CONFLICTS OF INTEREST}

Declared none.

\section{REFERENCES}

1. Li S, Lin S, Daggy BP, Mirchandani HL, Chien YW. Effect of HPMC and carbopol on the release and floating properties of gastric floating drug delivery system using factorial design. Int J Pharm 2003;253:13-22.

2. Arora S, Ali J, Ahuja A, Khar RK, Baboota S. Floating drug delivery systems: A review. AAPS PharmSciTech 2005;6:E372-90.

3. Chien YW, Shoufeng Li, Lin S, Daggy BP. Effect of formulation variables on the floating properties of gastric floating drug delivery system. Drug DevInd Pharm 2002;28:783-79.

4. Toda T, Eliasson E, Ask B, Inotsume N, Rane A. Roles of different CYP enzymes in the formation of specific fluvastatin metabolites by human liver microsomes. Basic ClinPharmacolToxicol 2009;105:327-32.

5. Sirbu C, Tomuta I, Achim M, Rus LL, Vonica L, Dinte E. Quantitative characterization of powder blends for tablets with indapamide by near infrared spectroscopy and chemometry. Farmacia 2014;62:48-57.

6. Funami T, Fang Y, Noda S, Ishihara S. Nakauma M, Draget KI, et al. Rheological properties of sodium alginate in an aqueous system during gelation in relation to super molecular structures and $\mathrm{Ca}^{2+}$ binding. Food Hydrocoll 2009;23:1746-55.

7. Tokumura T, Machida Y. Preparation of amoxicillin intragastric buoyant sustained-release tablets and the dissolution characteristics. J Control Release 2006;110:581-6.

8. Chavanpatil MD, Jain P, Chaudhari S, Shear R, Vavia PR. Novel sustained release, swellable and bioadhesivegastroretentive drug delivery system for ofloxacin. Int J Pharm 2006;316:86-92.

9. Nur AO, Zhang JS. Captopril floating and/or bioadhesive tablets: Design and release kinetics. Drug DevInd Pharm 2000;26:965-9.

10. Piyakulawat $P$, Praphairaksit N, Chantarasiri N, Muangsin N. Preparation and evaluation of chitosan/carrageenan beads for controlled release of sodium diclofenac. AAPS PharmSciTech 2007;8:E97.

11. Reddy KV, Nagabhushanam MV. The role of needle in formulation of $\mathrm{pH}$ sensitive swellable microbeads prepared with hydrophilic polymers for atorvastatin and their characterization studies. Int J App Pharm 2017:9:20-30.

12. Peppas NA. Analysis of fickian and non-fickian drug release from polymers. Pharm ActaHelv 1985;60:110-1

13. Pawar S. Formulation and evaluation of garlic powder loaded floating matrix tablet. Int J Pharm PharmSci 2019;11:17-21 